\title{
Reflexiones sobre la contabilidad ambiental en México
}

\author{
PATRICIA Rivera \\ GUILlERMO FolADORI"
}

\begin{abstract}
Mexico has two measuring systems for sustainability: the Sistema de Cuentas Económicas y Ecológicas (System of Economic and Ecological Accounts) which includes environmental measurements in the Cuentas Nacionales (National Accounts), and the Indicadores de Desarrollo Sustentable (Sustainable Development Indicators) which take into account economical, ecological, social and institutional variables. In this study we analyse the main methodological aspects of these tools and their results in terms of sustainability, we also mention some of their theoretical and methodological limitations. The main conclusions are that the environmental situation in Mexico is deteriorating alarmingly, that the methodology of the Sistema de Cuentas Económicas y Ecologicas is not transparent and that the results, which are limited to ecological sustainability, are a faint reflection of the concept that development sustainability is all about.
\end{abstract}

Keywords: Sustainable Indicators, Sustainable Development, Green Accounts, Mexico.

\section{Resumen}

México cuenta con dos sistemas de mediciones de sostenibilidad: el Sistema de Cuentas Económicas y Ecológicas de México, que incorpora mediciones ambientales en las Cuentas Nacionales, y los Indicadores de Desarrollo Sustentable, que dan cuenta de variables económicas, ecológicas, sociales e institucionales. En este artículo realizamos un análisis de los principales aspectos metodológicos de este instrumental y de sus resultados en materia de sostenibilidad, y señalamos limitaciones teórico-metodológicas. Las principales conclusiones son que la situación ambiental de México tiende a deteriorarse alarmantemente, que la metodología del Sistema de Cuentas Económicas y Ecológicas no es transparente, y que sus resultados, al estar limitados a la sostenibilidad ecológica, son reflejos tenues de lo que el concepto de desarrollo sostenible pretende reflejar.

Palabras clave: indicadores de sostenibilidad, desarrollo sostenible, cuentas verdes, México.

*Doctorado en Estudios del Desarrollo, Universidad Autónoma de Zacatecas, México. Correos-e: aire_tierra11@yahoo.com.mx y fola@estudiosdeldesarrollo.net. 


\section{Introducción}

La introducción del concepto de desarrollo sostenible ${ }^{1}$ (DS) ha conducido a la elaboración de mediciones que intentan integrar los aspectos económico, social y ambiental. Estas mediciones requieren establecer indicadores y, en algunos casos, modificar los sistemas de cuentas nacionales. En este artículo se analiza la propuesta mexicana. Se muestran las características esenciales de su metodología, así como los principales resultados en materia ambiental. El caso mexicano es importante porque constituyó la primera prueba piloto por parte de las Naciones Unidas como tentativa de modificar las cuentas nacionales de los países para que consideraran la problemática ambiental. ${ }^{2}$

En este artículo se concluye que: $a$ ) la situación ambiental en México tiende a deteriorarse alarmantemente, más allá de las limitaciones de las metodologías analizadas; $b$ ) la metodología del Sistema de Cuentas Económicas y Ecológicas de México (SCEEM) no es transparente, porque no hace explícitos los valores con los que trabaja o las razones de la elección de variables, y $c$ ) resulta limitado utilizar instrumentos de contabilidad ambiental que privilegian lo ecológico sobre lo social, como es el caso de la metodología del SCEEM, cuando el propósito es dar elementos para poner en práctica el concepto de DS.

El artículo se divide en cinco secciones. En la primera se revisan las dos iniciativas de medición ambiental emprendidas por México. En la segunda se enfatiza en una de ellas, el sCEEM. En la tercera se plantean los avances en materia de Indicadores de Desarrollo Sostenible (IDS) de México. En la cuarta sección se analizan los principales resultados en el estado del ambiente que se derivan de las mediciones y que coinciden con otras estimaciones en la gravedad del problema. En la quinta sección se advierte sobre la falta de transparencia y las limitaciones de la metodología.

\footnotetext{
${ }^{1}$ Sostenible y sustentable se utilizan en el texto como sinónimos.

${ }^{2}$ Los periodos en que se ha elaborado el SCEEM son los siguientes: 1985-1990, 1985 1992, 1985-1996, 1993-1997, 1993-1998, 1993-1999, 1995-2000, 1996-2001 y $1997-$ 2002, los cuales están disponibles en forma impresa. La serie 1985-1990 fue la prueba piloto y se encuentra disponible sólo en medios magnéticos (disquete) (INEGI, 2005).
} 


\section{Las iniciativas de medición ambiental emprendidas por México}

La introducción del concepto de Ds ha conducido a la elaboración de mediciones que pretenden integrar los aspectos económico, social y natural. Estas mediciones requieren indicadores y, en algunos casos, hacer modificaciones a los sistemas de cuentas nacionales. Las mediciones ambientales han ido cobrando importancia mundial con diferentes grados de avance y desarrollo en cada país (véase anexo). México se incorporó a la Organización para la Cooperación y el Desarrollo Económico (OCDE) en 1994, lo que lo obligó a realizar reportes ambientales periódicos (OECD, 2005). En ese marco, México desarrolló dos iniciativas: el SCEEM y los IDS. Ambas iniciativas son responsabilidad del Instituto Nacional de Estadística, Geografía e Informática (INEGI) y tienen cobertura nacional (Nieto, 2002). También están basadas en los lineamientos de la Comisión de Desarrollo Sostenible (CDS) de las Naciones Unidas (Claude, 1997: 127; Nieto, 2002: 12).

El SCEEM es una cuenta satélite dedicada al ambiente y elaborada como una extensión del Sistema de Contabilidad Nacional, y tiene la intención de integrar las estadísticas económicas y ambientales (INEGI, 2004).

La finalidad del SCEEM es compilar y generar estadísticas e indicadores que describan el estado y los cambios en los recursos naturales y el ambiente, y que puedan ser valuados monetariamente para incorporar la dimensión ambiental a la contabilidad nacional. Esta información serviría para medir los avances del país en términos de sostenibilidad, incluyendo mediciones que reflejen la protección, prevención y conservación del ambiente, y que ayuden a diseñar y poner en marcha estrategias y políticas de DS que faciliten la toma de decisiones con criterio ambiental (Claude, 1997: 97; INEGI, 1999; Martínez, 2000: 98; Martínez, 2002: 247; Nieto, 2002: 12).

Por su parte, la segunda iniciativa, los IDS, es resultado de la colaboración de varias dependencias gubernamentales, ${ }^{3}$ y tiene como finalidad probar el paquete de indicadores generados por la Comisión de Desarrollo Sostenible de las Naciones Unidas en México (INEGI, 2000b: 3; Nieto, 2002: 12). El propósito es pro-

Comisión Nacional del Agua (CNA), Secretaría de Medio Ambiente y Recursos Naturales (Semarnat), Instituto Nacional de Pesca (INP), Procuraduría Federal de Protección al Ambiente (Profepa), Secretaría de Energía, Secretaría de Desarrollo Social (Sedesol) y Secretaría de Salud (ss). 
porcionar a los expertos y al público en general un conjunto de indicadores que contribuyan tanto al conocimiento de la problemática de la sostenibilidad como a apoyar el diseño de estrategias y políticas de DS en el país; al mismo tiempo, sentar las bases metodológicas que permitan continuar el trabajo de elaboración y actualización de dichos indicadores (INEGI, 2000b: 3).

En términos generales, el objetivo de las dos iniciativas es brindar información que permita evaluar el estado del país en función del Ds. No obstante, mientras el SCEEM tiene el propósito de valuar monetariamente determinadas variables ambientales que no aparecen contabilizadas en el tradicional producto interno bruto (РІB), como es el caso de las reservas de minerales o el estado de contaminación del agua, los IDs incluyen una base más amplia de dimensiones e indicadores.

\section{El Sistema de Cuentas Económicas y Ecológicas de México (SCEEM)}

La Environment Statistics Section de la United Nations Statistics Division (Unstat), el Banco Mundial y el Programa de las Naciones Unidas para el Medio Ambiente trabajan, desde principios de los años noventa, en la elaboración de metodologías que unifiquen la contabilidad ambiental con los sistemas de cuentas nacionales. En 1993 se propuso el Sistema de Contabilidad Ambiental y Económica Integrada (SCAEI), explicado en el Manual para una Contabilidad Económica y Ambiental Integrada (MCEAI), y que tiene como finalidad la unificación de metodologías y comparaciones entre países. ${ }^{4}$ Cada país debe ajustar el sistema a sus características y condiciones. En México, el sistema ajustado se llama SCEEM. ${ }^{5}$

La esencia del SCEEM consiste en realizar un balance físico (cambios positivos y negativos) de los recursos naturales, de los costos ambientales de esos cambios y, también, del impacto eco-

${ }^{4}$ El INEGI (2004: XIII) señala que a pesar de los esfuerzos de la Organización de las Naciones Unidas (ONU) y los gobiernos de varios países para impulsar el cálculo del PIB ecológico a partir de los Sistemas de Contabilidad Nacional (SCN), sólo se cuenta con una docena de estudios oficiales, y son aún menos los países que calculan este índice de manera periódica. Entre los países que aplican el SCAEI están, además de México (1996), Filipinas (1997), Japón (1997) y Corea (1998) (Martínez, 2002).

${ }^{5}$ El caso mexicano es el más destacado de las experiencias latinoamericanas por ser el país cuyos técnicos participaron activamente en la conformación de una metodología estándar, que fue publicada por las Naciones Unidas en 1993 (MCEAI) (Claude, 1997: 98; Martínez, 2000; Naciones Unidas, 2002). 
nómico de dichos costos en las variables macroeconómicas (Claude, 1997: 97; INEGI, 2000a; Nieto, 2002: 12; Martínez, 2000: 98; Martínez, 2002). La cobertura del SCEEM es la siguiente: petróleo, recursos forestales (maderables) y cambios en el uso del suelo, recursos hídricos (agua subterránea), erosión del suelo, contaminación del agua, contaminación del suelo y contaminación del aire. Los tres primeros son recursos naturales cuya disponibilidad -al menos estimada o probada- y cambios cuantitativos registrados es posible conocer. ${ }^{6}$ Los cuatro temas restantes están relacionados con la degradación del ambiente y se registran como flujos, debido a que es difícil conocer su existencia y disponibilidad en un momento determinado (INEGI, 2004). ${ }^{7}$

El método de medición empleado por el INEGI consideró, al igual que el utilizado en los indicadores macroeconómicos, dos entradas, una por la producción y otra por el gasto, lo cual permite realizar cálculos para una misma variable con más de un procedimiento. Esto posibilita evaluar su consistencia (INEGI, 2004). ${ }^{8}$

Para incorporar riqueza material no monetarizada a la contabilidad económica, fue necesario establecer conceptos apropiados. La modificación al concepto de activos significa, en términos teóricos, que los recursos naturales dejan de ser considerados bienes libres y de oferta ilimitada para convertirse en bienes escasos y posibles de ser monetizados (Claude, 1997: 102; INEGI, 2000a).

\subsection{El concepto ampliado de "activos" como instrumento para relacionar recursos físicos con medidas monetarias}

Para monetizar los balances físicos y transitar a un nuevo concepto metodológico de la contabilidad ambiental fue necesaria la redefinición del concepto de "activos" que tradicionalmente se empleaba en la contabilidad macroeconómica (Claude, 1997:

\footnotetext{
${ }^{6}$ Se calculan tanto las existencias como los flujos. De esta forma se determina el agotamiento de los últimos mediante balances físicos anuales para cada recurso (INEGI, 2004).

${ }^{7} \mathrm{Su}$ tratamiento consiste en calcular los flujos que afectan el ambiente y alteran su calidad natural como resultado de las actividades de producción de bienes y servicios, y de distribución y de consumo humano (INEGI, 2004).

${ }^{8}$ En la contabilidad económica, el cálculo del PIB se realiza por dos métodos: la producción y el gasto. El método de la producción es: PIB = PTBS-CI (1), donde: PTBS = producción total de bienes y servicios, y $\mathrm{CI}=$ consumo intermedio (materias primas, materiales, energía y servicios utilizados en el proceso de producción). Este método expresa la generación de bienes y servicios finales a partir del esfuerzo interno de la economía, por lo que no incluye las importaciones. El método del gasto o demanda final es: PIB $=C+G+F B K+X-M(3)$, donde: $C=$ consumo privado (consumo de bienes
} 
102; INEGI, 2000a). ${ }^{9}$ El INEGI (2000a) los clasifica en activos económicos producidos (Kep), activos económicos no producidos (Kenp), y activos ambientales no producidos (Kanp).

Los activos económicos producidos, o Kep, son bienes para consumo directo, o bienes de capital que sirven para obtener un producto en forma de otros bienes y servicios (INEGI, 2000a). Estos activos son los tradicionalmente considerados en la contabilidad económica; por ejemplo, construcciones, maquinaria y equipo e instalaciones.

Los activos económicos no producidos, o Kenp, son aquellos que, no obstante ser utilizados en la producción, no provienen de proceso productivo alguno. Se trata de activos de origen natural que poseen la característica de que puede establecerse propiedad sobre ellos (son factibles de monopolio), y desde un punto de vista metodológico son cuantificables (Claude, 1997: 102; INEGI, 2000a). Estos activos no son tradicionalmente considerados en la contabilidad económica hasta tanto no ingresan a un proceso productivo y se convierten en activos producidos. La virtud de considerarlos en la contabilidad refleja la preocupación por valorar las variaciones de stock. Este stock, aun en su forma natural, constituye riqueza física para el país; son ejemplos los bosques (naturales explotados), el petróleo y el suelo.

Por último, los activos ambientales no producidos, o Kanp, son activos de origen natural que son afectados por la actividad económica, pero poseen características tales que no permiten la apropiación. Incluyen funciones que cumple la naturaleza en los ciclos de vida y productivos, pero cuya capacidad no se transforma directamente en mercancía ni ingresa como valor en las mercancías (INEGI, 2000a). Es claro que tampoco estos activos son corrientemente considerados por la contabilidad económica. En este caso, la intención de la metodología es valorar determinadas funciones

y servicios de hogares residentes); $G=$ consumo de bienes y servicios del gobierno; $F B K=$ inversión bruta (formación bruta de capital, incluye la inversión total en activos fijos más la variación de existencia); y $X-M=$ balanza comercial de bienes y servicios con el exterior (exportaciones netas). Por este método, el PIB representa la demanda final de bienes y servicios, compuesta por demanda interna $(C+G+F B K)$ más exportaciones netas (X-M) (INEGI, 2004).

${ }^{9}$ Según la contabilidad económica convencional, el concepto de activos refleja el capital que participa con su valor comercial en los procesos productivos (INEGI, 2000a). Los activos se clasifican en: $a$ ) reales, cuando tienen valor por sí mismos (mercaderías, muebles), y $b$ ) financieros, cuando tienen valor por lo que representan (billetes, depósitos bancarios) (Moreno, 2003). 
ambientales que no entran como materia prima directa en los procesos productivos, pero cuya calidad es decisiva para la vida humana y cuya degradación incide sobre la dinámica económica, como es el caso del agua, el aire y los bosques naturales.

$\mathrm{Al}$ asignársele a los recursos naturales y al ambiente la categoría de activos, su tratamiento en la contabilidad económicoambiental es similar al de los activos económicos producidos. Pero para ello es necesario asignar a los recursos un valor monetario y calcular los costos por agotamiento y degradación con el fin de incluirlos en los flujos monetarios y calcular el producto interno neto ecológico (PINE). En otras palabras, el PINE muestra la integración del concepto de acumulación neta y los costos por usos ambientales (agotamiento y degradación ambientales).

\subsection{Proceso de acumulación de activos económicos y ambientales}

Las variables relacionadas con los recursos naturales y el ambiente permiten identificar tanto los cambios en los activos como la ampliación del concepto de acumulación. El concepto de $\mathbf{a c u}$ mulación se refiere al cambio en el balance de activos económicos producidos por la incorporación de nuevos bienes de capital, a lo cual se le denomina acumulación neta de activos económicos producidos (Almagro, 2004: 117; INEGI, 2004: 8). Las cuentas ambientales registran dos elementos adicionales al balance de los activos económicos no producidos:

a) El primero se refiere al cambio en la inversión de los activos económicos no producidos (' $I_{\text {Kenp }}$ ), el cual resulta de la transferencia de activos ambientales a las actividades económicas; por ejemplo, la transferencia de la tierra, de bosques silvestres o de reservas minerales al uso en actividades económicas. A su vez, estos cambios pueden incluir pérdidas de activos económicos no producidos por concepto de contaminación o erosión de suelo.

b) El segundo elemento representa el agotamiento de los activos económicos no producidos $\left(A G_{\text {Kenp }}\right)$, disminución de los recursos naturales debido a su explotación (prácticamente imposible de recuperar); por ejemplo, el petróleo.

En suma, el concepto de acumulación neta de activos económicos $\left(A_{b e}\right)$ agrupa no sólo los cambios en los activos producidos 
e inversión bruta $\left(I_{b}\right)$, sino también las modificaciones que registran los activos económicos no producidos, lo cual se expresa de la siguiente manera:

$$
A_{b e}=I_{b}-\left(I^{\prime} I_{k e n p}+A G_{k e n p}\right)
$$

Otro elemento incorporado en el concepto de acumulación neta es el que se refiere a los activos ambientales, denominado acumulación neta de activos ambientales $\left(A_{\text {kanp }}\right)$, que representa los cambios o afectaciones en la calidad de los recursos ambientales resultantes de la actividad. Aunque los activos ambientales no forman parte del proceso productivo, se ven afectados por él e incurren tanto en un nivel de agotamiento $\left(A G_{k a n p}\right)$-por ejemplo, bosques y fauna- como en el proceso de degradación $\left(\mathrm{DG}_{k a n p}\right)$-aire, agua o suelo-. A su vez se incluyen cambios en activos ambientales no producidos (' $I_{\text {kanp }}$ ) (Almagro, 2004: 117; INEGI, 2004: 8).

$$
A_{k a n p}=' I_{k a n p}-\left(A G_{k a n p}+D G_{k a n p}\right)
$$

Existen dos tipos de agotamiento: el de recursos naturales no producidos $\left(\mathrm{AG}_{\text {kenp }}\right)$ y el de recursos ambientales $\left(\mathrm{AG}_{\text {kan }}\right)$.

La suma de las identidades (1) y (2) representa la acumulación bruta total, que incluye: activos económicos producidos y no producidos, más el agotamiento de los recursos naturales y la degradación del ambiente.

Con base en la propuesta de clasificación de activos y su acumulación se llevó a cabo la cuantificación de los balances y/o flujos en unidades físicas y, posteriormente, en unidades monetarias para los temas referentes al agotamiento del petróleo, los recursos forestales, el uso y erosión del suelo y la contaminación del agua y del aire, considerándose el impacto que la actividad productiva tiene sobre ellos. Así, aplicando esta metodología, desde el punto de vista de la producción pueden calcularse los costos por agotamiento y degradación, y, a partir del gasto, determinarse los activos no producidos y las inversiones.

\subsection{Cálculo del PINE ajustado ambientalmente por el método de la producción y el gasto}

Para la determinación del PINE fue necesario el acopio, evaluación y procesamiento de una gran cantidad de información. Diversos métodos de valoración fueron aplicados a dicha informa- 


\section{Cuadro 1}

Cálculo del pINE por medio de la producción y el gasto

\begin{tabular}{|c|c|}
\hline Método & Procedimiento \\
\hline Producción & $\begin{array}{l}\text { PINE }=\text { PIN }-(\mathrm{Cag}+\mathrm{Cdg}) \\
\text { Donde: } \\
\text { PIN }=\text { producto interno neto } \\
\text { Cag }=\text { costos por agotamiento de recursos naturales } \\
\text { Cdg }=\text { costos por degradación del ambiente }\end{array}$ \\
\hline Gasto & $\begin{array}{l}\text { PINE }=C+G+\left(A_{b e}+A_{\text {kanp }}\right)+(X-M) \\
\text { Donde: } \\
C+G=\text { consumo final } \\
A_{\text {be }}=I_{b}-\left(I_{\text {kenp }}+A G_{\text {kenp }}\right) \text { acumulación neta de } \\
\text { activos económicos } \\
A_{\text {kanp }}={ }^{\prime} I_{\text {kanp }}-\left(\mathrm{AG}_{\text {kanp }}+\mathrm{DG}_{\text {kanp }}\right) \text { acumulación neta } \\
\text { de activos ambientales } \\
X-M=\text { exportaciones }- \text { importaciones }\end{array}$ \\
\hline
\end{tabular}

Fuente: Elaboración propia con los datos de INEGI (2000a) y Almagro (2004).

ción con el propósito de confrontar y analizar los resultados derivados de cada uno de ellos, y así elegir el que expresara de manera más precisa los costos ambientales y los componentes de los balances (INEGI, 2004) (véase cuadro 1).

\subsubsection{Método de producción}

El método de producción se determina a partir del PIB, restándosele el agotamiento de los recursos naturales y el deterioro del ambiente. Se contabiliza el agotamiento en los siguientes recursos: petróleo, recursos forestales (maderables) y cambios en el uso del suelo, así como los recursos hídricos (agua subterránea) (véase cuadro 2).

Para el cálculo del agotamiento de petróleo, recursos forestales y cambios de uso de suelo se utiliza el método de la renta neta, que es el gasto que se requiere realizar para mantener el recurso natural en condiciones tales que continúe generando ingresos (INEGI, 2004).

En relación con el petróleo, se calculan los costos por el agotamiento de los yacimientos de reservas (su disminución en millones de barriles). ${ }^{10}$ Para los recursos forestales se calcula la tala

10 Para el agotamiento del petróleo se dispuso de información publicada por la empresa Petróleos Mexicanos (Pemex), referente a las reservas de hidrocarburos del país. Y, complementariamente, de información del Instituto Mexicano del Petróleo (IMP) (INEGI, 2004). 


\section{Cuadro 2}

\section{Variables y métodos utilizados en el cálculo del PINE por el método de producción}

\begin{tabular}{lll}
\hline Tema & Elemento cuantificado $\quad$ Método \\
\hline
\end{tabular}

Agotamiento

Petróleo

Costos por agotamiento

Renta neta

de las reservas de petróleo

en millones de barriles

Recursos forestales Tala de bosques maderables (maderables) y y disminución de áreas cambios de uso forestales por destinarse a otros usos económicos (costo unitario promedio a pagar por reposición de un metro cúbico de madera en rollo)

Costo de remediación (estimado por medio de suelo

Costo rollo)

Recursos hídricos Costo equivalente a devolver (agua subterránea), el nivel de agua a los mantos sobreexplotación acuíferos en millones de $\mathrm{m}^{3}$

\section{Degradación}
Erosión del suelo Costos de fertilización requeridos para mantener la productividad de la tierra (pérdida de nutrientes en miles de toneladas)
Contaminación Residuos sólidos en miles Renta neta de suelo de toneladas
Contaminación Descargas de agua residual Renta neta de agua en millones de $\mathrm{m}^{3}$

\section{Contaminación} de aire
Emisiones primarias en
Renta neta miles de toneladas

Renta neta producción, mantenimiento, reforestación y cuidado de la planta)

Renta neta

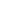


de bosques maderables atendiéndose a la disminución de $\mathrm{m}^{3}$ de madera en rollos, y para el agotamiento de agua subterránea se asumió que el costo ambiental es equivalente a inyectar agua en los mantos acuíferos en aquella fracción igual a la diferencia entre volumen de extracción y la recarga natural (INEGI, 2004: 10).

Para el caso de la degradación se incluyen la erosión del suelo y la contaminación de agua, aire y suelo, los cuales se determinan con el método de costos de mantenimiento. La erosión del suelo es calculada a partir de los costos de fertilizantes necesarios para mantener la productividad de la tierra, y la contaminación de agua, aire y suelo se obtiene considerando las erogaciones que serían necesarias para reducir o eliminar dicha contaminación (INEGI, 2004). ${ }^{11}$

\subsubsection{Método del gasto}

El segundo método para calcular el PINE se obtiene con base en las variables del gasto, de los activos económicos producidos y no producidos, así como la relativa a los activos ambientales (INEGI, 2004: 10). Los métodos más utilizados para asignar el valor a los activos no producidos son: renta neta, costo de uso ${ }^{12}$ y costo de mantenimiento. Los dos primeros se aplican alternativamente a los aspectos de agotamiento, y el tercero a los de degradación (INEGI, 2004: 8).

La nueva cobertura de los activos y de sus balances en el concepto de acumulación neta, así como la incorporación de los costos ambientales (agotamiento y degradación), son los factores que permiten la ampliación del sistema contable hacia el Sistema de Cuentas Económicas y Ecológicas Integrado.

\section{Los avances en materia de Indicadores de Desarrollo Sostenible (IDS) de México}

Ante la convocatoria realizada por la CDS en 1995 para llevar a cabo una prueba piloto mundial de elaboración de IDS, el Instituto Nacional de Ecología (INE) y el INEGI comenzaron, por separa-

\footnotetext{
${ }^{11}$ La contaminación del agua se determina por las descargas de agua residual y se mide en millones de $\mathrm{m}^{3}$; la contaminación del aire se mide por emisiones primarias en miles de toneladas; y, por último, la contaminación de suelo se mide por los residuos sólidos municipales generados en miles de toneladas (Almagro, 2004: 108; INEGI, 2004: 14).

${ }^{12}$ El método costo de uso valúa el recurso con base en su costo por agotamiento, estimado como una parte del valor presente del ingreso neto esperado en la vida útil del recurso, con la condición de que dicha parte sea reinvertida para obtener un ingreso permanente en el futuro (INEGI, 2004).
} 
do, a involucrarse de manera no oficial. En 1997, México se sumó formalmente al programa de trabajo de IDs, junto a otros 21 países que habían decidido participar en dicha prueba piloto mundial. De las dos instituciones mexicanas participantes, el INE quedó con la atribución de diseñar la política ambiental de México, mientras que el INEGI quedó con la responsabilidad de integrar el sistema de información estadística y geográfica (INEGI, 2000b: 25).

Una vez unificado el trabajo se identificaron vacíos, duplicaciones e inconsistencias metodológicas y de información. Después se distribuyeron los indicadores por temas o categorías según la responsabilidad de cada institución. Son cuatro las áreas en que se distribuyen los indicadores: ambientales, económicos, sociales e institucionales. Al INEGI le correspondió la elaboración de los indicadores económicos y sociales, mientras que al INE, los ambientales. Los indicadores institucionales fueron distribuidos entre las dos instituciones según la disponibilidad de información (INEGI, 2000b: 26).

Como resultado, México logró generar 113 indicadores de sostenibilidad de un total propuesto de 134. Esa cantidad integra 97 elaborados de acuerdo con su correspondiente hoja metodológica, más otros 16 elaborados alternativamente a la metodología propuesta. De los no evaluados restantes, seis están en proceso de desarrollo y otros 15 no responden a las prioridades nacionales de información (INEGI, 2000b: 29). ${ }^{13}$ En la figura I se ilustra la distribución de los indicadores en las cuatro áreas temáticas $;^{14}$ pero, además, se muestra que la gran mayoría de los

${ }^{13}$ Los indicadores en proceso de desarrollo son: en materia social: 1) índice del grado de pobreza, y 2) índice del grado de pobreza al cuadrado; en materia económica: 3 ) intensidad de uso de materiales; 4) total de asistencia oficial para el desarrollo, dada o recibida, como porcentaje del PIB; 5) cantidad de financiamiento nuevo o adicional para el desarrollo sustentable, y 6) ayuda a la cooperación técnica. Los no disponibles o que no responden a prioridades nacionales de información son: en materia social: 1) proporción de químicos potencialmente peligrosos monitoreados en los alimentos; 2) área y población de asentamientos urbanos formales e informales; 3) área habitable por persona, y 4) precio de vivienda en proporción al ingreso; en materia ambiental: 5) descargas de petróleo en aguas costeras; 6) descargas de nitrógeno y fósforo en aguas costeras; 7) índice de algas; 8) administración descentralizada de los recursos naturales en el nivel local; 9) población que vive por debajo de la línea de pobreza en tierras áridas; 10) índice de vegetación obtenido de imágenes de satélite; 11) cambio de la población de áreas montañosas; 12) uso sustentable de los recursos naturales en las áreas montañosas; 13) bienestar de poblaciones de áreas montañosas; 14) gasto de investigación y desarrollo en biotecnología, y 15) existencia de regulaciones o lineamientos de bioseguridad (INEGI, 2000b).

${ }^{14}$ Hay indicadores que se encuentran disponibles para los ámbitos nacional, estatal y municipal. Sin embargo, al efectuar la sumatoria de los nacionales no coinciden con los 113 indicados, debido a que el indicador social Pérdidas humanas y económicas 


\section{Figura I}

\section{Clasificación por área de los indicadores generados por México}

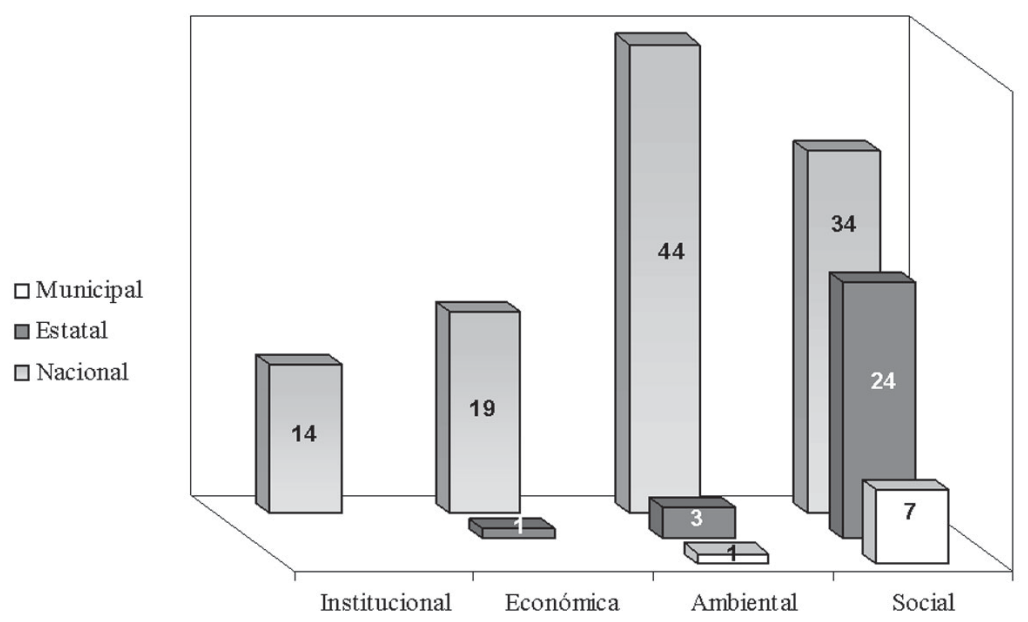

Fuente: Elaboración propia con base en INEGI (2000b).

indicadores sólo registran información nacional, lo cual conduce a generar diagnósticos de niveles macro, y dificulta políticas regionales, estatales y municipales.

La información estadística de los indicadores incluye una breve definición, la categoría temática según la Agenda 21, la clasificación de ubicación según el esquema Presión-Estado-Respuesta (PER) ${ }^{15}$ y el propósito del indicador (INEGI, 2000b: 30; Quiroga, 2001).

debidas a desastres naturales y el indicador institucional Consejos nacionales para el desarrollo sustentable no se encuentran clasificados en ningún ámbito geográfico.

${ }^{15}$ Existen diferentes marcos ordenadores utilizados para clasificar los indicadores ambientales. Entre ellos podemos encontrar: el Presión-Estado-Respuesta (PER); Marcos jerárquicos: Principios, Criterios e Indicadores (PCI); el Fuerza-Estado-Respuesta (FER); Presión-Estado-Impacto/Efecto-Respuesta (P-E-I/E-R); etc.). El marco ordenador PER es uno de los más usados por su utilidad en la toma de decisiones. Su generalización parte de haber sido desarrollado y recomendado originalmente por la OCDE (1993), y el Scientific Committee of Problems of the Environment (SCOPE), y compartido por agencias internacionales como Unstat o la Statistical Office of the European Comunities (Euroestat). Este marco estructura los indicadores en tres categorías, como su nombre lo indica: los indicadores de Presión tratan de responder sobre las causas del problema, por ejemplo, emisiones o acumulación de desechos; los indicadores de Estado responden sobre la situación del ambiente, como ejemplo tenemos la calidad del aire urbano, la concentración de sustancias tóxicas o el número de especies en peligro; y, por último, 
Se cuenta con dos hojas generales de reporte de los indicadores. ${ }^{16}$ La primera se refiere al estado de desarrollo de los indicadores en cuanto a información contenida, e incluye: la elaboración de indicadores según la definición de CDS, indicadores en desarrollo e indicadores no disponibles, además de la institución responsable en la elaboración de cada indicador. La segunda hoja de reporte muestra la naturaleza y características en torno a la información involucrada; básicamente informa: si es parte del programa nacional de información, el método de captación de los datos, la frecuencia de actualización, la cobertura geográfica y la disponibilidad y formato de acceso (INEGI, 2000b: 30 y 31).

Las categorías temáticas económica y social presentaron menores dificultades para su elaboración, debido a los avances que el INEGI ya tenía en esos rubros. La categoría institucional sólo requirió esfuerzos adicionales de búsqueda de información, pero todos los indicadores ya están disponibles. Finalmente, la categoría ambiental fue la que presentó dificultades, por no existir información básica previa o por falta de claridad o insuficiencia conceptual (INEGI, 2000b: 33) (véase cuadro 3).

\section{Cuadro 3}

Balance de los indicadores propuestos por la CDS y los generados por México

\begin{tabular}{|c|c|c|c|c|c|c|c|c|}
\hline \multirow{3}{*}{$\begin{array}{l}\text { Categoría } \\
\text { del indicador }\end{array}$} & \multicolumn{8}{|c|}{ Tipo de indicador } \\
\hline & \multicolumn{2}{|c|}{ Presión } & \multicolumn{2}{|c|}{ Estado } & \multicolumn{2}{|c|}{ Respuesta } & \multicolumn{2}{|c|}{ Total } \\
\hline & $\begin{array}{l}0 \\
0 \\
\stackrel{H}{0} \\
0 \\
0 \\
0 \\
0 \\
01\end{array}$ & 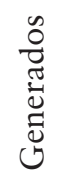 & 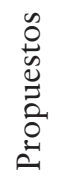 & 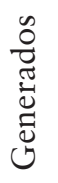 & 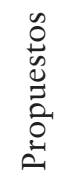 & 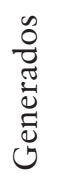 & 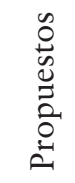 & 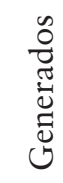 \\
\hline Social & 13 & 13 & 21 & 16 & 7 & 6 & 41 & 35 \\
\hline Económico & 8 & 8 & 12 & 10 & 3 & 1 & 23 & 19 \\
\hline Ambiental & 22 & 18 & 18 & 14 & 15 & 12 & 55 & 44 \\
\hline Institucional & 0 & 0 & 3 & 3 & 12 & 12 & 15 & 15 \\
\hline Total & 43 & 39 & 54 & 43 & 37 & 31 & 134 & 113 \\
\hline
\end{tabular}

Fuente: INEGI (2000b).

los indicadores de Respuesta revelan lo que se hace para resolver o enfrentar el proble$\mathrm{ma}$, tales como compromisos internacionales, tasas de reciclaje o eficiencia energética (Quiroga, 2001: 108 y 109).

${ }^{16}$ Publicadas por el INEGI (2000b: 41-50), Indicadores de Desarrollo Sustentable en México en sus anexos I y II. 


\section{El estado del ambiente según los cálculos del PINE y los Indicadores de Desarrollo Sustentable}

De acuerdo con el SCEEM 1997-2002 (véase cuadro 4), los activos forestales maderables y las reservas de petróleo muestran una disminución media anual por agotamiento de 0.87 y $2.40 \%$, respectivamente. El agua subterránea, por su parte, presenta una tasa media de sobreexplotación de $2.23 \%$ para el mismo periodo.

Se calcula una tasa promedio anual de emisión de contaminantes que afectan el aire, el suelo y el agua de 6.07\% (bióxido de azufre, óxido de nitrógeno, hidrocarburos, monóxido de carbono y partículas suspendidas). Por su parte, los residuos sólidos de hogares y actividades productivas crecen a una tasa anual de

\section{Cuadro 4}

Balances físicos de los recursos naturales 1997-2002

\begin{tabular}{llrrr}
\hline Recursos $^{1}$ & Unidades de medida & 1997 & 2002 & TMCA $^{2}$ \\
\hline Forestal (bosques) & $\begin{array}{l}\text { Millones de m }{ }^{3} \text { de } \\
\text { madera en rollo }\end{array}$ & 2,377 & 2,275 & $(0.87)$ \\
$\begin{array}{l}\text { Petróleo } \\
\text { (reservas totales) }\end{array}$ & Millones de barriles & 56,505 & 50,032 & $(2.40)$ \\
$\begin{array}{l}\text { Agua } \\
\text { (disponibilidad) }\end{array}$ & Millones de m ${ }^{3}$ & $(5,949)$ & $(6,642)$ & $(2.23)$ \\
$\begin{array}{l}\text { Contaminación del } \\
\text { aire por emisiones } \\
\text { primarias }\end{array}$ & Miles de toneladas & 40,155 & 53,924 & 6.07 \\
$\begin{array}{l}\text { Contaminación del } \\
\text { suelo por residuos } \\
\text { sólidos } \\
\text { municipales }\end{array}$ & Miles de toneladas & 31,512 & 35,820 & 2.60 \\
$\begin{array}{l}\text { Contaminación } \\
\text { del agua (descargas } \\
\text { de agua residual) }\end{array}$ & Millones de m & & & \\
$\begin{array}{l}\text { Erosión de suelos } \\
\text { (pérdida de nutrientes) }\end{array}$ & Miles de toneladas & 637,098 & 768,730 & 3.83 \\
\hline
\end{tabular}

${ }^{1}$ Los recursos forestales, el petróleo y el agua fueron calculados determinando el balance de cierre $=$ balance apertura +/- cambios; las contaminaciones de aire, suelo y agua, por medio de flujo de emisiones contaminantes; y la erosión de suelo, por medio de flujo.

${ }^{2}$ Tasa media de crecimiento anual.

Fuente: INEGI (2004). 
2.60\%, lo cual contamina el suelo. Además, un estudio de erosión arrojó una tasa promedio anual de $3.83 \%$.

Por otra parte, un estudio de agua realizado por el INEGI (2004:13), y que incluye indicadores de contaminación tales como demanda bioquímica de oxígeno, demanda química de oxígeno, sólidos suspendidos, sólidos disueltos totales, sólidos totales y nitrógeno, refleja un crecimiento promedio de contaminación de $2.4 \%$ anual.

En su conjunto, el impacto económico del deterioro ambiental en el PIB o, -dicho de otra manera, los Costos Totales de Agotamiento y Degradación Ambiental (CTADA)-, equivale a 10.5\% promedio anual, y representa las erogaciones que la sociedad en su conjunto tendría que efectuar para remediar o prevenir el daño ambiental (INEGI, 2004: 13) (véase cuadro 5).

Más alarmantes son las proyecciones, ya que de continuar las tasas de crecimiento o las condiciones actuales de agotamiento y degradación, todo el PIB del año 2002 debería haber sido destinado a resarcir los daños de los últimos 10 años (INEGI, 2004: 13).

La comparación entre los gastos de protección ambiental -que son de 33,099 millones de pesos y corresponden a 0.53\% del PIB-, y los gastos derivados de la degradación y agotamiento, -que son de 623,075 millones de pesos y corresponden a 10.5\% del PIB (INEGI, 2004)- muestra que existe un enorme rezago en recursos económicos destinados a la sostenibilidad ambiental. ${ }^{17}$

El PINE se basa exclusivamente en indicadores ambientales. No así los IDS, que incluyen indicadores ambientales, institucionales, económicos y sociales. Dada la amplitud en áreas y cantidad de indicadores que el IDs incluye, se considera que México cumple con los requisitos internacionales de información ambiental gracias a un sistema de señales que facilita la evaluación del progreso del país hacia el Ds y que es la base metodológica para continuar con la elaboración y actualización en el trabajo de los indicadores (Quiroga, 2001: 9). Sin embargo, el hecho de que los indicadores se presenten de manera desagregada dificulta hacerse una imagen global de la situación ambiental, o jerarquizar dentro del conjunto aquellos más significativos para el país.

Los pobres resultados en materia de sostenibilidad ambiental obtenidos por el INEGI son confirmados por otras estimaciones. Con los datos generados en el sceEM, Martínez (2002) desarrolló el Índice de Sustentabilidad Ambiental (ISA) - una metodología pro-

${ }^{17}$ Esta comparación de los gastos de protección ambiental con los CTADA indica que para mantener el entorno ecológico del año 2002, es necesaria una inversión de 17.82 veces más de gastos de protección ambiental. 


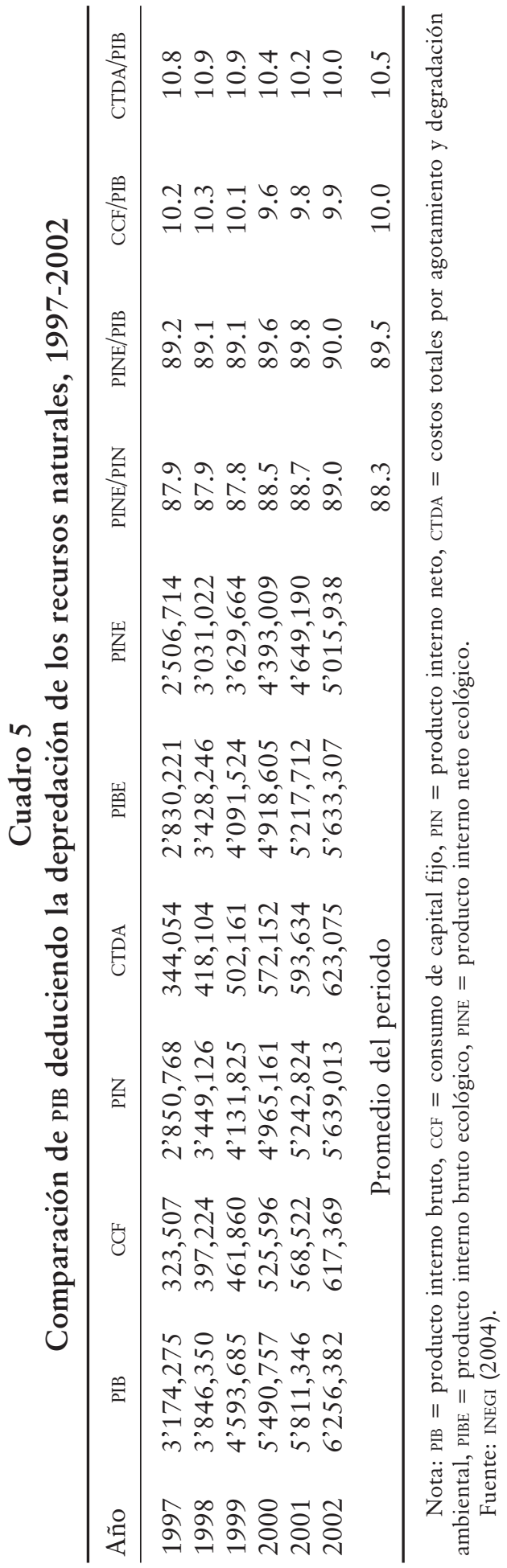


puesta por Pearce y Atkinson (1993)-. El ISA asume que el capital natural puede ser sustituido plenamente por el capital producido. De allí que la economía resulta sostenible cuando se ahorra más que la depreciación combinada de las dos formas de capital (véase cuadro 6).

\section{Cuadro 6 \\ Índice de Sustentabilidad Ambiental (ISA)}

\begin{tabular}{l}
$\qquad \mathrm{Z}=(\mathrm{S} / \mathrm{Y})-(\mathrm{M} / \mathrm{Y})-(\mathrm{N} / \mathrm{Y})$ \\
\hline $\mathrm{Z}=$ Indicador de sustentabilidad \\
$\mathrm{S}=$ Ahorro \\
$\mathrm{M}=$ Valor de la depreciación de capital producido \\
$\mathrm{N}=$ Valor de la depreciación de capital natural \\
$\mathrm{Y}=$ Ingreso
\end{tabular}

Fuente: Pearce y Atkinson (1993).

En este índice, Pearce y Atkinson (1993) proponen tres valores para los resultados obtenidos. Si $Z$ es mayor que 0 se está en una situación donde la economía está creciendo de manera sostenible. Si $Z$ es menor que 0 , la economía es no sostenible. Por último, cuando $Z$ es igual 0 se trata de una economía marginalmente sostenible. Al aplicar el índice de Sustentabilidad Ambiental de Pearce y Atkinson a México, Martínez (2002) encuentra que este país está en situación "no sustentable", a excepción del año $1990 .{ }^{18}$ En el cuadro 7 se resumen las críticas de Martínez al sCEEM.

Almagro (2004) también hizo un recuento de los avances de la contabilidad ambiental mexicana. Efectuó algunas comparaciones con los resultados del SCEEM y concluyó que la tendencia de México es preocupante en relación con el objetivo de alcanzar un desarrollo con sostenibilidad. Esta tendencia es confirmada por el INEGI (2004) en su cuadro de Balances Físicos de los Recursos Naturales 1997-2002, al mostrar el agotamiento de recursos naturales y la degradación ambiental en unidades físicas.

El Environmental Sustainability Index (ESI) una iniciativa del Foro Económico Mundial, y es desarrollado por las universidades de Yale y de Columbia. Su objetivo es conformar un índice mejor que el del PIB para medir el avance de los países en el camino hacia la sostenibilidad. Utiliza 76 variables que se agregan por temas en

\footnotetext{
${ }^{18}$ Martínez (2002) considera para su cálculo la serie de años de 1988 a 1996.
} 


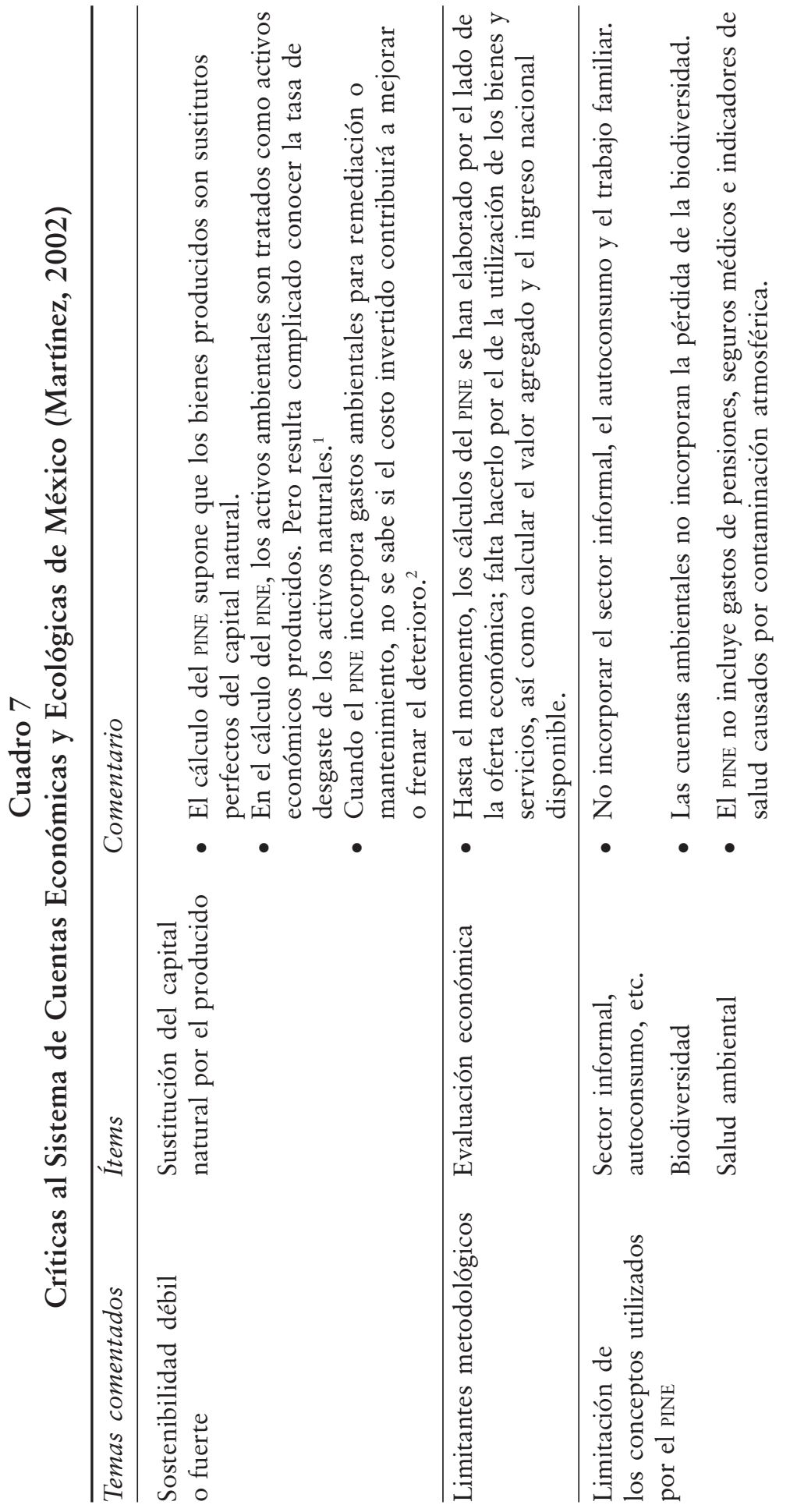




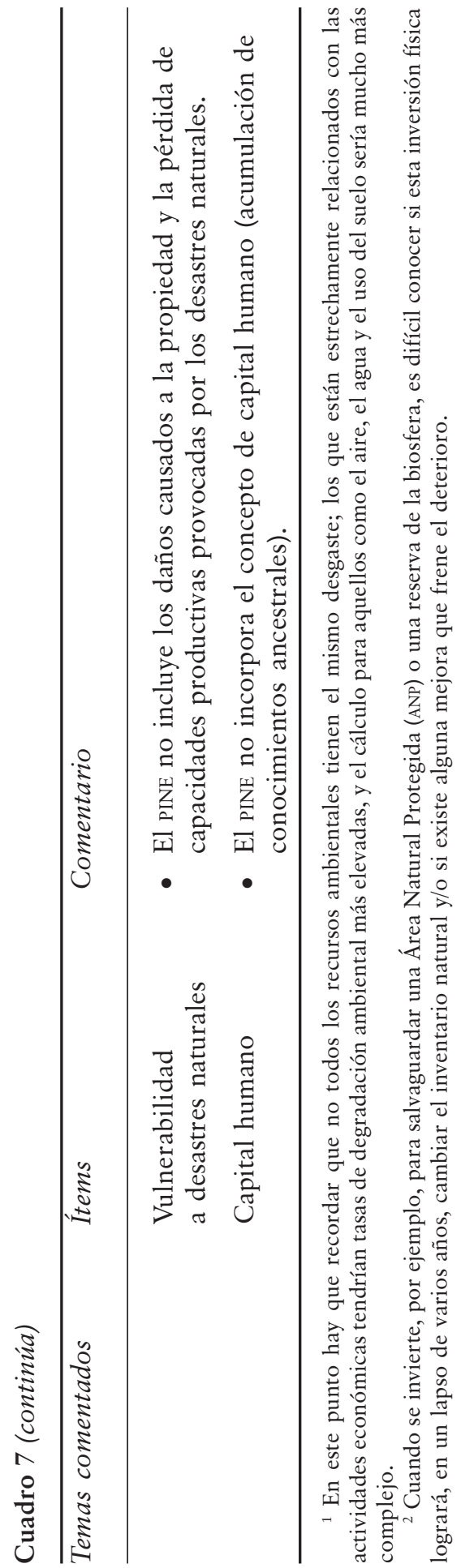


21 indicadores, que abarcan aspectos relativos a recursos naturales, contaminación, manejo ambiental, contribuciones a la protección del ambiente mundial y capacidad de la sociedad para mejorar su desempeño ambiental en el tiempo (Esty et al., 2005). En la tercera versión de este índice, divulgada en enero de 2005, México quedó en el lugar 95 en una lista de 146 países. El primero fue Finlandia, y el último, Corea del Norte. Estados Unidos quedó en el lugar 45. Dentro del conjunto de valores calculados por país para las diferentes variables, el menor valor que obtuvo México fue en la administración global, la cual manifiesta que el país no es cuidadoso de sus presiones ambientales transfronterizas, por lo que fue castigado en el puntaje. Donde México obtuvo mejor puntaje fue en la reducción de la vulnerabilidad humana, una variable que incluye salud ambiental, sustento humano básico y reducción de la vulnerabilidad frente a desastres naturales. En suma, los resultados arrojados por el ESI 2005 colocan a México en una posición desventajosa, abajo del promedio general de los países analizados, y señalan la necesidad de esfuerzos relativos a la gestión ambiental nacional.

\section{Limitaciones metodológicas}

El primer problema con el que se enfrenta quien pretende entender la metodología utilizada en el SCEEM es la falta de transparencia en la información. En términos sociológicos y administrativos, la metodología adolece de falta de accountability, o de un mecanismo de rendición de cuentas que explique el procedimiento seguido. Según Schedler (2004), la rendición de cuentas incluye tanto la obligación de los funcionarios de informar y justificar sus decisiones públicamente (answerability), como la sanción en caso de violación de deberes públicos (enforcement). En México, Ugalde (2002) considera la rendición de cuentas como una obligación. La falta de transparencia en la información se manifiesta de dos maneras. Por un lado, no está explícita en la metodología la razón por la cual se eligen determinadas variables para medir el estado del ambiente. En realidad, la única información que se brinda para justificar la elección de variables es haber revisado la información estadística disponible en instituciones públicas y privadas. ${ }^{19}$

19 “[...] para delimitar la cobertura temática del estudio, es necesario conocer con mayor precisión posible las características y disponibilidad de la información ambiental del país. Para ello, se llevan actividades de exploración, recopilación, evaluación y 
Los documentos son claros en cuanto a las fuentes teóricas y metodológicas que se utilizan, como en el caso de la Agenda $21 ;^{20}$ también en el hecho de que la metodología es un esfuerzo internacional y, en ese sentido, se ajusta a varios criterios y a la necesidad de adecuarse a los lineamientos del SCN de $1993 .{ }^{21}$ De igual forma, es claro el principio rector de incorporar variables en las cuales la actividad productiva y de consumo impacte de forma significativa los ecosistemas. Pero no hay explicaciones de por qué determinadas actividades económicas impactan en mayor o menor medida en los ecosistemas; ${ }^{22}$ tampoco sobre cuáles son los criterios mediante los cuales se eligen unas variables y no otras. ${ }^{23}$

Por otro lado, tampoco es transparente la forma en que se realizan las estimaciones. El lector interesado en conocer cuál es el costo de remediación del agotamiento de los recursos forestales (maderables), ${ }^{24}$ por ejemplo, se pregunta: ¿cómo calcularon el valor de reposición de una unidad de madera en rollo? Esta falta de valores para cada variable también impide que la metodología sea utilizada para información municipal o estatal que pueda obtenerse. La contabilidad ecológica llega a un resultado numérico agregado nacional sin ofrecer información estatal, y, lo que es peor, sin establecer los valores para cada una de las varia-

consulta sobre las estadísticas de dependencias del sector público e instituciones privadas, académicas y de carácter social [...] se realizan consultas y reuniones de discusión técnica con especialistas y expertos del sector académico, centros de investigación, universidades e institutos" (INEGI, 2004: 1).

20 "[...] el SCEEM tiene la finalidad de hacer operativos los conceptos de crecimiento y desarrollo sostenible, de acuerdo con lo postulado por la Agenda 21, en lo referente a un Sistema de Contabilidad Ambiental" (INEGI, 2004: 17).

21 "[...] el SCEEM, como cuenta satélite, adopta los lineamientos del SCN 1993 al momento de incorporar los recursos naturales y el ambiente al entorno económico" (INEGI, 2004: 10).

22 " [...] que la incorporación de los temas obedece al impacto que la actividad productiva tiene sobre ellos así como el consumo en la distribución de bienes y servicios" (INEGI, 2004: 10).

${ }^{23}$ Una metodología para la elección eficaz de variables es la que parte de las funciones ambientales. La matriz de funciones ambientales es ampliamente utilizada en el Análisis Ambiental Estratégico (AAE) (Barbier et al., 1994; Sadler, 1996; DalalClayton y Sadler, 1999; Seht, 1999; Kessler, 2003; Nierynck, s/f; UNEP, s/f).

24 "El cual considera los requerimientos mínimos en los cuales tendríamos que invertir para devolverle a los bosques un monto similar a los recursos maderables con que contaba antes de ser afectado por las actividades económicas. Esto permite fijar el costo unitario promedio a pagar por la reposición de un metro cúbico de madera en rollo; el cual se ha estimado incluyendo factores como costos de producción, mantenimiento, reforestación y cuidado de la planta hasta obtener un árbol aprovechable económicamente, en términos maderables. Para definir los costos de producción y mantenimiento..." (INEGI, 2004: 3). 
bles. Al lector no le queda más alternativa que confiar y contentarse con generalidades acerca de las fuentes utilizadas. ${ }^{25}$

Otro tipo de comentario crítico que puede hacerse a las mediciones ambientales mexicanas es el bies ecologista de la metodología. Los problemas de insostenibilidad social no son considerados por sí mismos, sino en la medida que causan insostenibilidad ecológica. Lo que la metodología mide es el uso y la velocidad con que se explotan y degradan los recursos naturales mediante las variables de agotamiento y degradación, pero nada hay sobre las causas sociales que los originan. De esta manera, la metodología sólo considera la manifestación técnica de un fenómeno social. La medición de la degradación del suelo, por ejemplo, remite a prácticas agropecuarias insostenibles. Pero a estas técnicas se llega por una presión de determinadas condiciones sociales. La pobreza y la competencia mercantil, por ejemplo, son de las más importantes causas sociales que propician ese tipo de técnica ecológicamente insostenible. Al repararse exclusivamente en la manifestación del fenómeno -la degradación del suelo o el agotamiento de los recursos naturales-, se capta solamente la causa técnica y su manifestación ecológica, lo que tiene claramente que ver con la sostenibilidad ecológica o ambiental. Pero nada se dice sobre la sostenibilidad social, que también es parte integrante y con igualdad de jerarquía del concepto de Ds (Foladori y Tommasino, 2005).

Haciendo un análisis de aquellos indicadores de la categoría social de los IDS puede identificarse que muchos de ellos son de dudosa eficacia, derivada de los sesgos en su cálculo y de la información que se recaba. Los que están basados en promedios, por ejemplo, dicen poco sobre la situación real del país, ya que ocultan la diferenciación e iniquidad; es el caso, por ejemplo, del PIB por habitante. Otros tienen dudoso origen, como las tasas de migración, que sólo recogen los movimientos de población dentro de la República Mexicana, cuando el flujo migratorio internacional neto anual aumentó 12 veces en el curso de las últimas tres décadas y media, y cuando pasó de un promedio anual de 28 mil migrantes en los años sesenta, a 138 mil en los setenta, a 235 mil en los ochenta, y a 328 mil en los noventa (Conapo, 2004).

${ }^{25}$ En el caso de las fuentes de los recursos forestales: “[...] entre las principales estadísticas se destacan el Informe de la situación del Medio Ambiente 2002 Semarnat; Inventario Nacional Forestal de Gran Visión 1991-1992 y el Inventario Forestal Nacional, 2000, la producción maderable por Entidad Federativa y Grupo de Producto, así como información actualizada sobre las actividades de reforestación proporcionadas por la Semarnat" (INEGI, 2004: 3). 
Otros indicadores, sin embargo, muestran la cruda realidad; por ejemplo, cuando se señala que por debajo de la línea de pobreza ha estado más de $15 \%$ de la población desde el año de 1984, y que el porcentaje ha aumentado hasta el último dato del año 1992. También es alarmante que el Índice de Gini, que muestra la desigualdad en el ingreso, haya aumentado entre 1984 (0.4292) y $1994(0.4770)$, aunque tuviese un retroceso en la última cifra correspondiente a 1996 (0.4558). Las diferencias entre género son notorias en todos los indicadores, como en el ingreso, donde las mujeres ganan alrededor de $70 \%$ de lo que ganan los hombres. Otro tasa alarmante es la de la mortalidad infantil: 28 por cada mil a mediados de los noventa.

El resultado general de los datos del PINE, y de los que brindan los IDS, no muestra una mejoría en el camino hacia el DS mexicano. Considérese un solo dato social, aunque sumamente elocuente: la migración internacional. La migración de mexicanos hacia Estados Unidos ha sido una constante por más de un siglo, pero los niveles a los que ha llegado en la última década y el impacto que tiene actualmente en la economía obliga a una reflexión. México es el principal emisor de migrantes en el mundo, con un flujo promedio anual hacia Estados Unidos de 400,000 personas y una población de origen mexicano establecida en ese país superior a los 26 millones. Se trata además del principal receptor de remesas del mundo. Para 2004, éstas alcanzaron 16,600 millones de dólares (La Jornada, 2005). Es decir, México vive de la venta de sus recursos no renovables y está convirtiendo a su fuerza de trabajo, un recurso tradicionalmente renovable, en uno no renovable como consecuencia de la creciente migración sin retorno.

En suma, es claro que la intención del PINE es 'corregir' las cuentas nacionales e incorporar la riqueza material no monetarizada, pero el mensaje que transmite inevitablemente oculta todo tipo de problemas de sostenibilidad social y, por tanto, muchos del Ds. Este bies ecológico no puede ser superado con el sistema de IDs que México también elabora, y que incluye indicadores económicos, sociales e institucionales, además de los ambientales. No puede serlo porque mientras el sCEEM consolida la información y la presenta en un solo dato, al estilo del PIB, los IDS son más de cien, y al no presentar ningún tipo de agregación tienen la ventaja de no mezclar cosas diferentes, pero también la desventaja de ser menos contundentes al momento de divulgar los resultados. De manera que si a la información propiamente am- 
biental se le incorporan datos de sostenibilidad social, el panorama mexicano sería, en términos de DS, seguramente peor.

\section{Conclusiones}

Las mediciones ambientales cobran cada vez más importancia en el ámbito global al tratar de cristalizar el concepto de DS. México intenta reproducir los estándares internacionales de información ambiental por medio de sus iniciativas: las cuentas ambientales que amplían el concepto de desarrollo económico integrando los costos de agotamiento y degradación ambiental; y la generación de indicadores, los cuales son un punto de referencia para uniformar criterios en torno al concepto internacional de DS. A pesar de los avances que representan estas mediciones para México, no puede hablarse de una complementariedad entre ambas. Mientras el PINE corrige las cuentas nacionales incorporando la riqueza material no monetarizada mediante un dato consolidado y considerando exclusivamente los aspectos ambientales, los IDs incluyen aspectos económicos, sociales, institucionales y ambientales, sin presentar ningún tipo de agregación.

Los balances físicos de recursos naturales en el cálculo del PINE exponen un incremento en la erosión de suelos y en la contaminación de aire, agua y suelo, mientras que hay una disminución en recursos forestales, petróleo y agua subterránea, lo cual muestra la degradación y el agotamiento de recursos en México. A pesar de que sólo se integran ciertos recursos en el análisis, el impacto negativo de la actividad económica sobre los recursos naturales es contundente y muestra un deterioro mayor a $10 \%$ del PIB anual. Esto significa que México no solamente no mantiene su 'salud ambiental', sino que ya requeriría de 10\% anual de la actividad económica para reponer los daños. Considerando que muchos de estos daños son irreversibles, sea porque corresponden a extracción de recursos no renovables, como el caso del petróleo, sea porque ilustran sobre un grado de deterioro que hace inviable su fácil recuperación, como es el caso de la erosión en grados graves y muy graves, puede afirmarse que gran parte del daño ambiental es también irreversible.

Los IDS, por otra parte, ofrecen información, en la mayoría de los casos, sólo para el país, lo cual limita la generación de estudios en otros planos (estatal y municipal), y convierte en discutible la estimación de algunos indicadores. 
Los resultados desalentadores son confirmados por otras estimaciones que concluyen que la tendencia del país es preocupante en relación con el objetivo de alcanzar un desarrollo sostenible.

Lamentablemente, desde el punto de vista de los investigadores interesados y público profesional, la metodología empleada en el cálculo del PINE no es suficientemente transparente, porque no está explícita la razón de la elección de las variables y porque no da cuenta de los valores sobre los cuales se estiman los resultados de las variables. Además, este nuevo índice no considera problemas referentes a la sostenibilidad social, lo cual coloca a la ecología fuera de cualquier contexto social. 


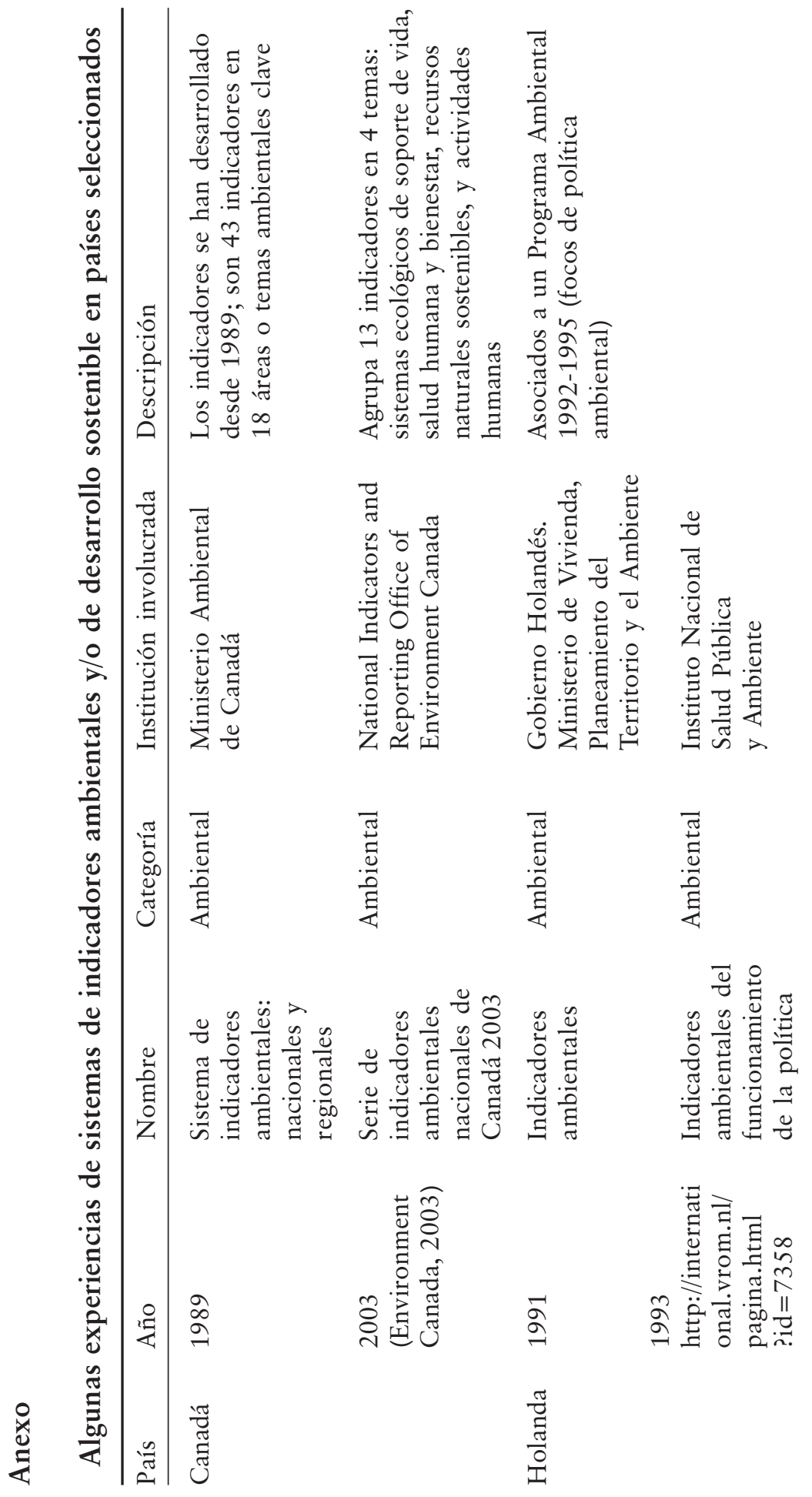




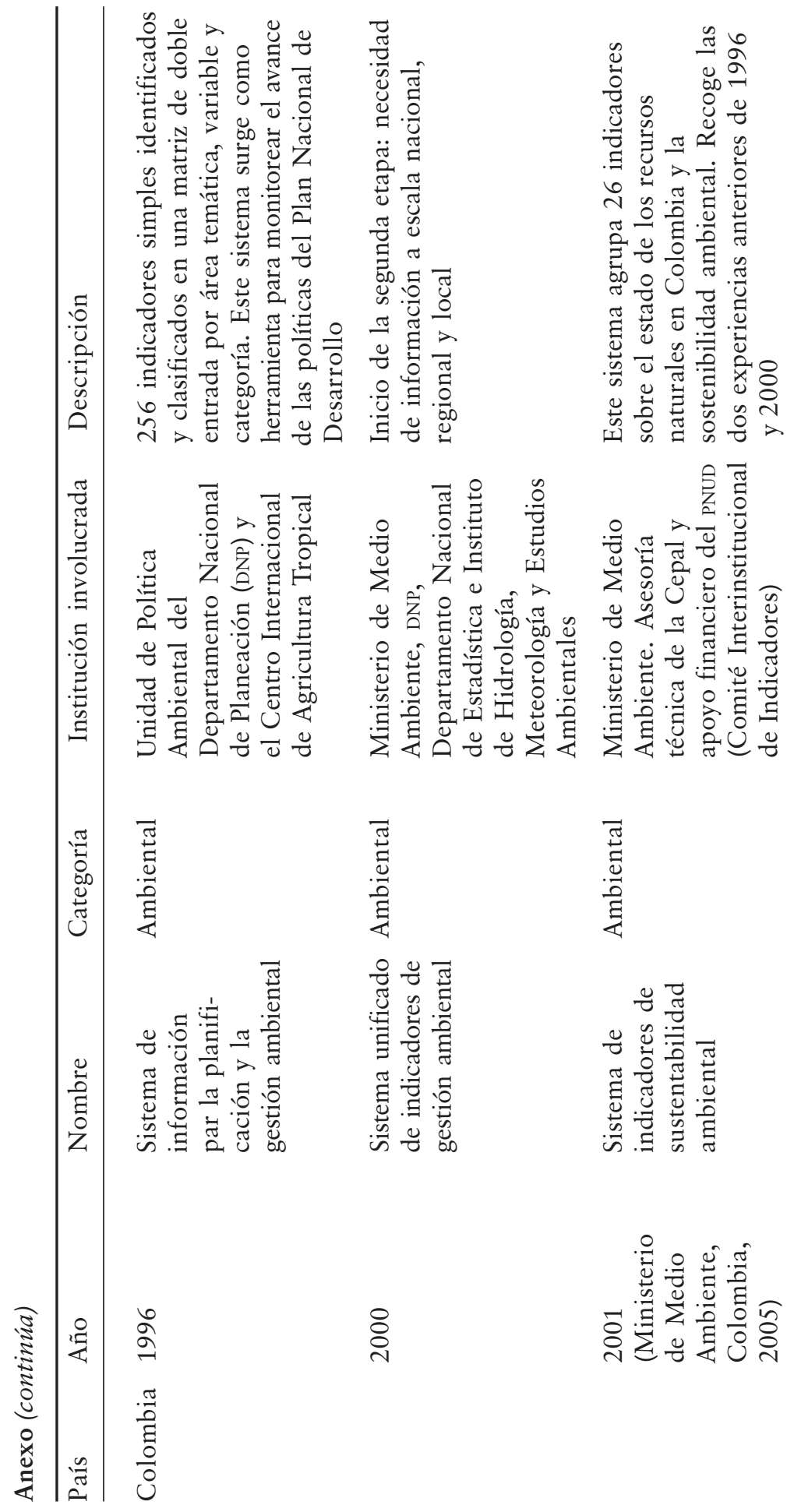




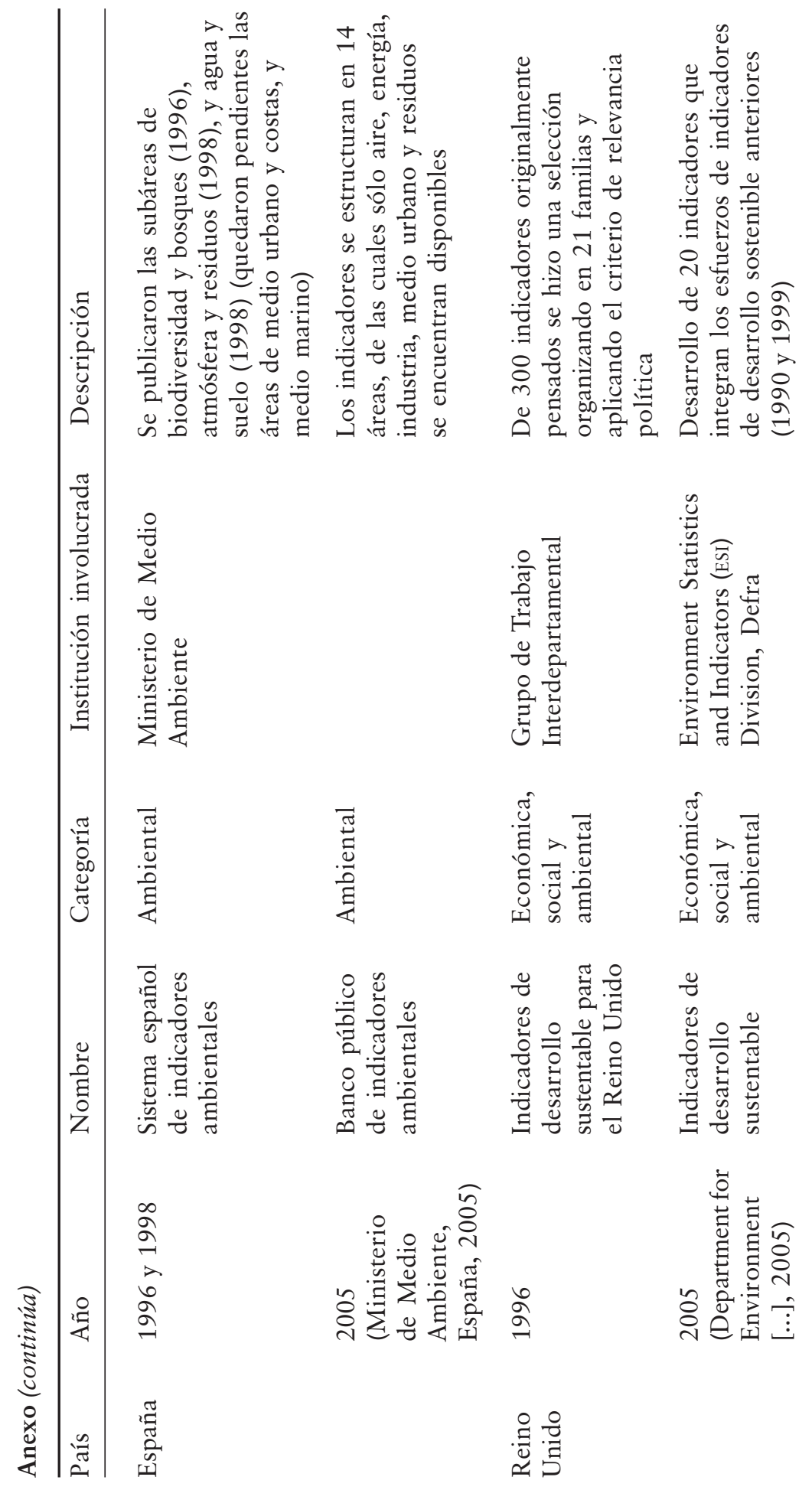




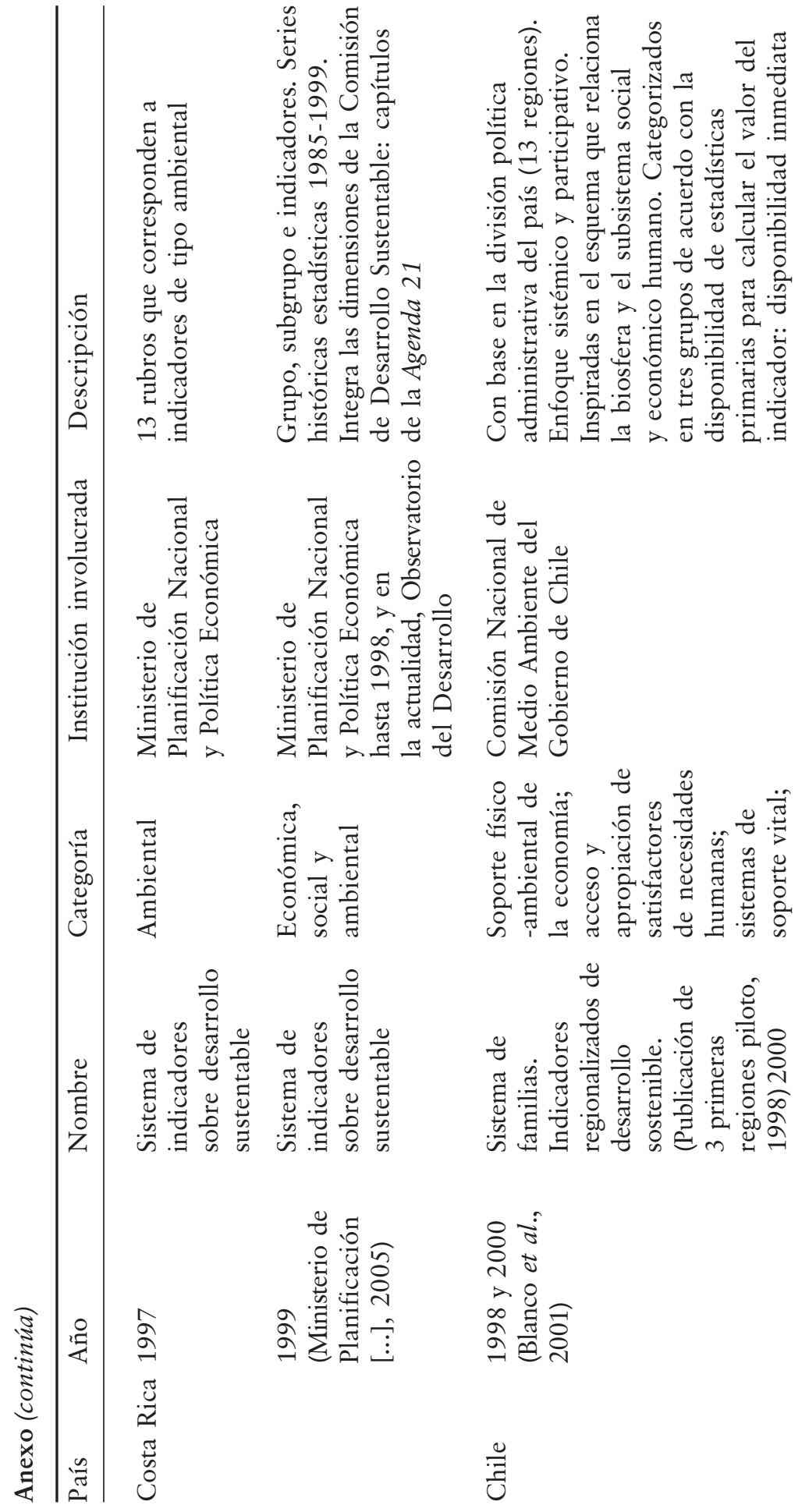




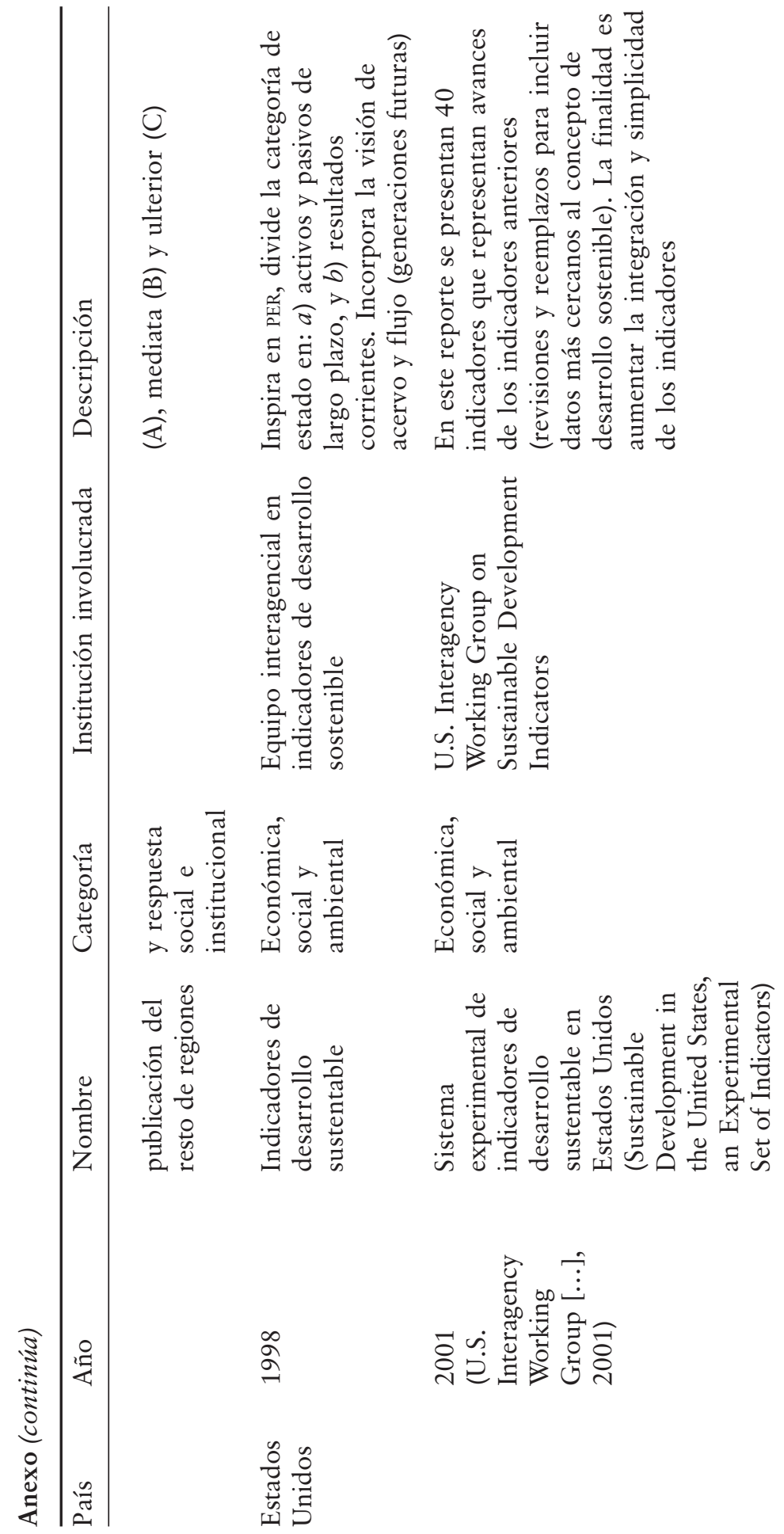




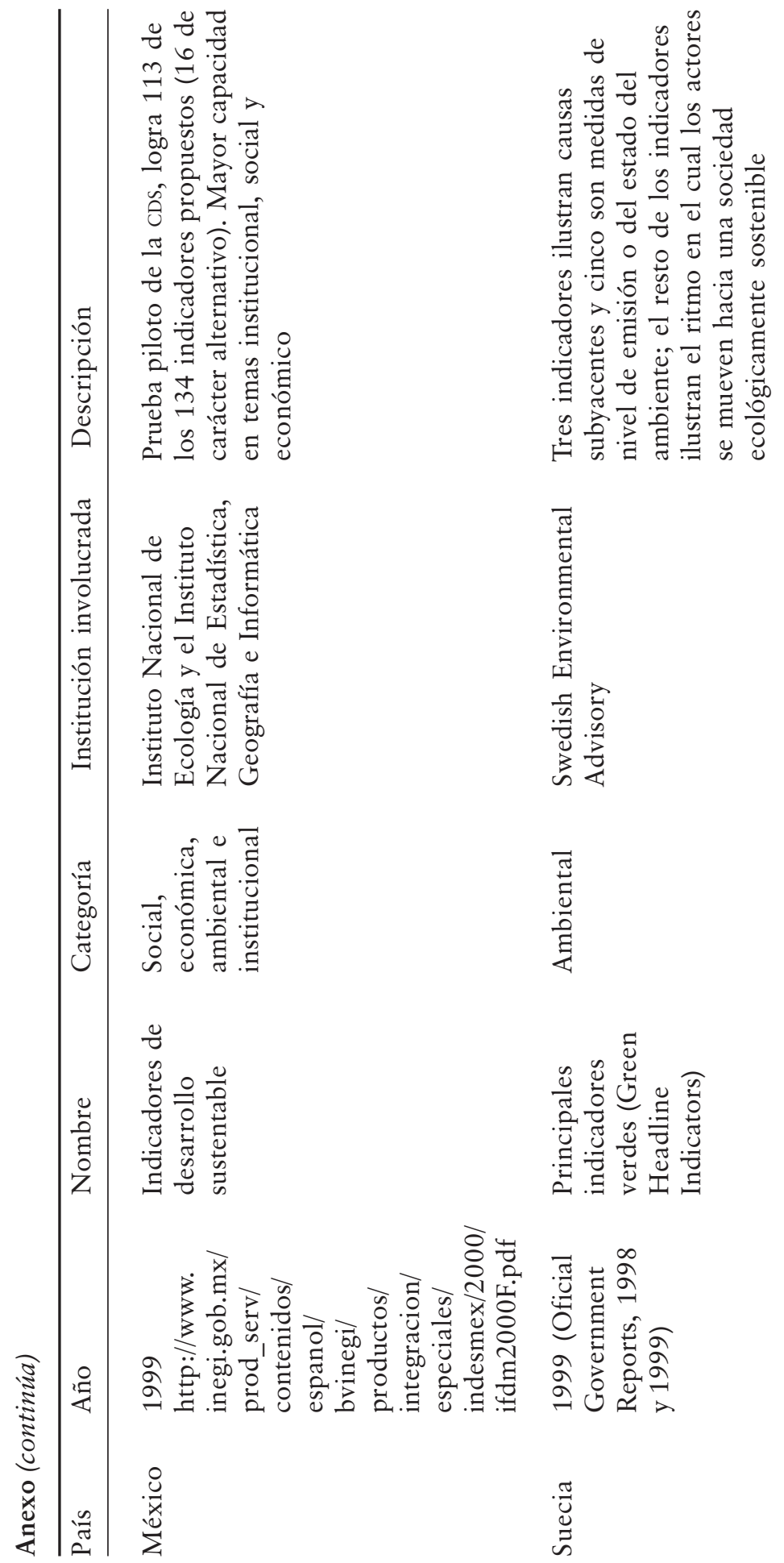




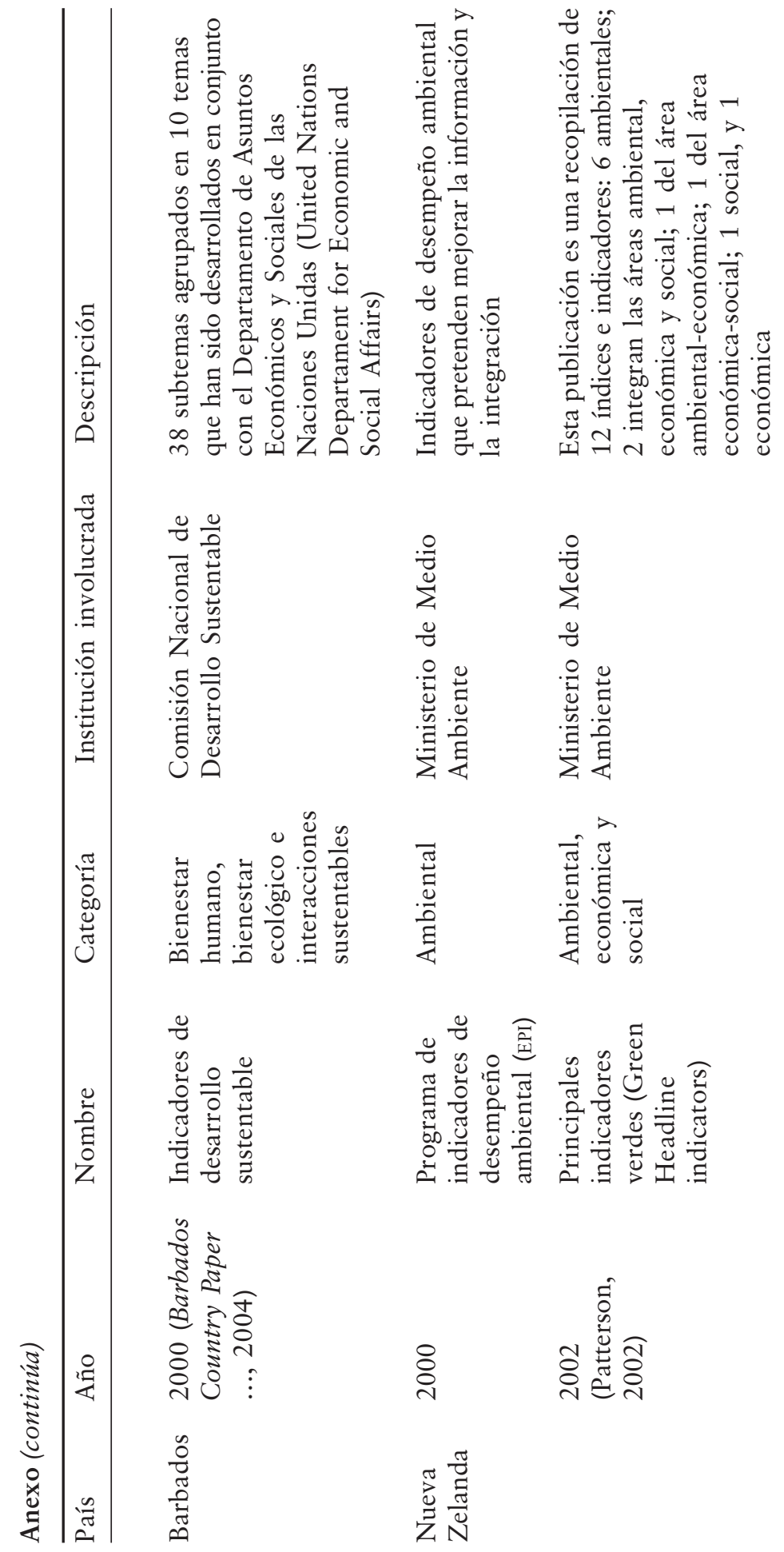




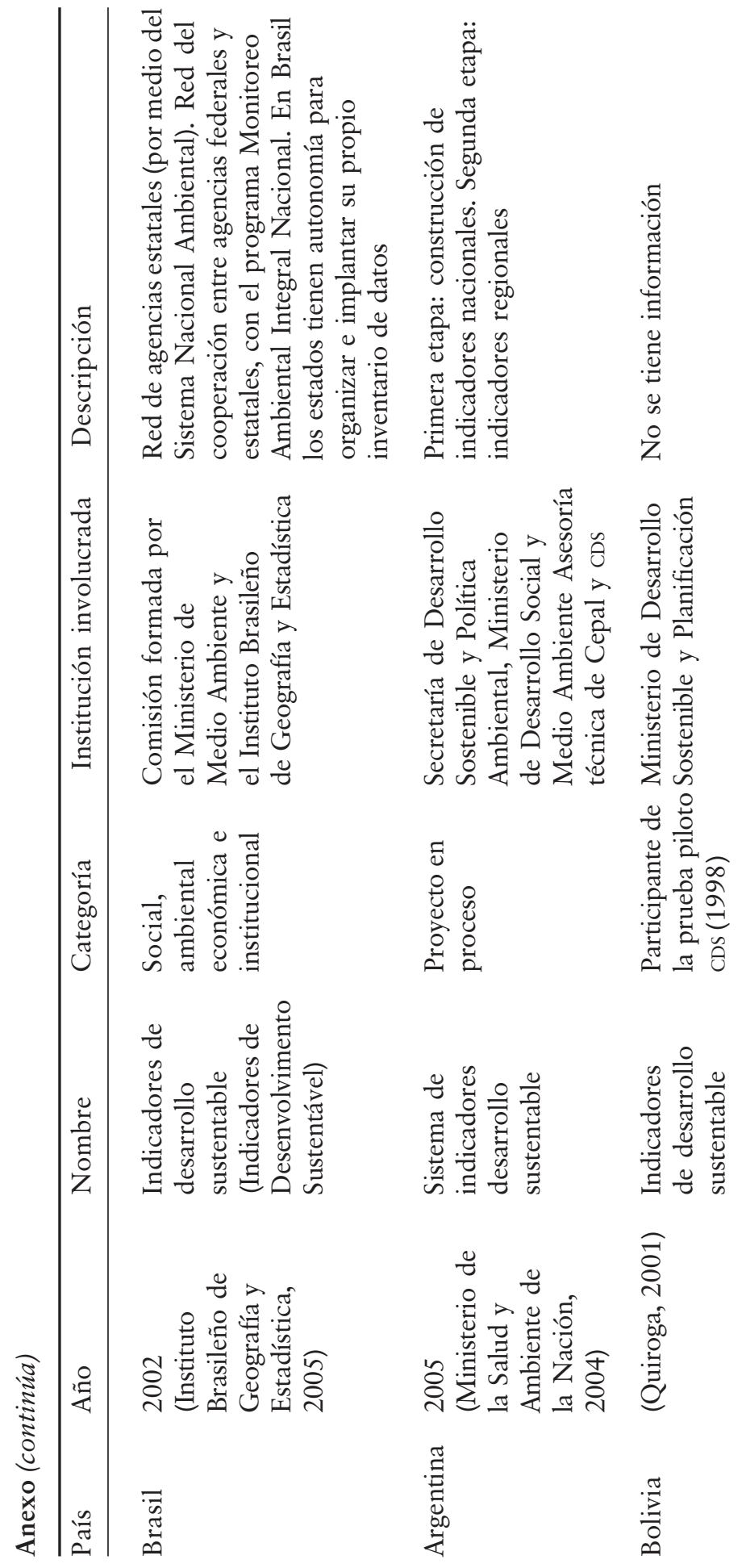




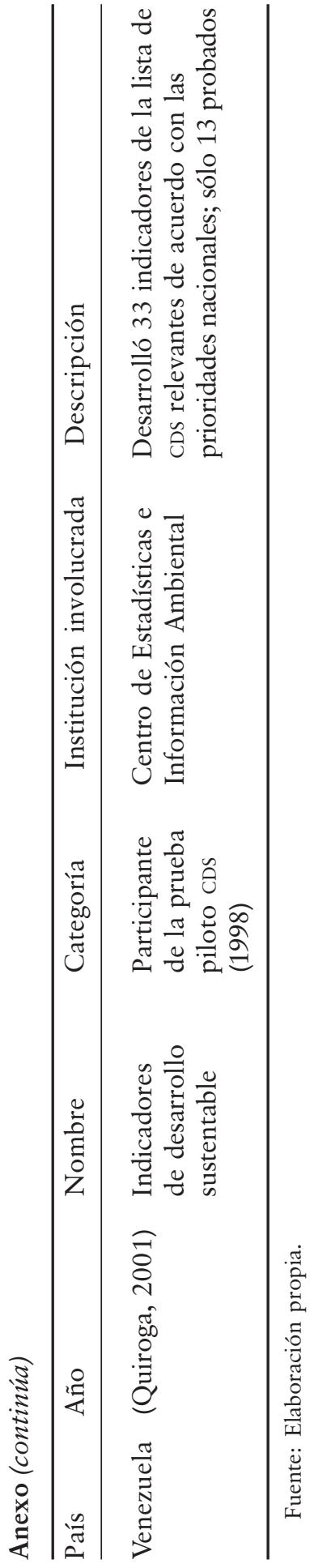




\section{Bibliografía}

Almagro, F. (2004), "Medición del desarrollo sustentable, reto de las cuentas nacionales. La experiencia de México en el cálculo del producto interno bruto ecológico", Problemas del Desarrollo, Revista Latinoamericana de Economía, 35 (139): 93-119.

Barbados Country Paper to the Regional Workshop on National Sustainable Development Strategies and Indicators of Sustainable Development (2004), http://www.oecs.org/esdu/ documents/IDP\%20Project/Country\%20Report\%20\%20Barbados.pdf, agosto de 2005.

Barbier, Edward, Joanne Burgess y Carl Folke (1994), Paradise Lost? The Ecological Economics of Biodiversity, Earthscan, Londres.

Blanco, Hernán, Françoise Wautiez, Ángel Llavero y Carolina Riveros (2001), Indicadores regionales de desarrollo sustentable en Chile: ¿Hasta qué punto son útiles y necesarios?, http://www.scielo.cl/scielo.php? pid=S0250$71612001008100005 \&$ script $=$ sciarttext \& $2 \operatorname{lng}=e s$, agosto de 2005 .

Claude, Marcel (1997), Cuentas pendientes: estado y evolución de las cuentas del medio ambiente en América Latina, Fundación Futuro Latinoamericano, http://nweb18.worldbank. org/ESSD/envext.nsf/44ByDocName/FundacionFuturo Lat in o m e ricano Cuentas Pendientesesta doyEvoluci\%C3\%B3ndelasCuentasdelMedioAmbienteen Am\%C3\%A9ricaLatina1997PDF549KB/\$FILE/Fundacion FuturoLatinoamericanoCuentas1997.pdf, marzo de 2005.

Conapo (Consejo Nacional de Población) (2004), Pérdida neta anual por migración a Estados Unidos por periodo, 19602003, http://www.conapo.gob.mx/mig_int/series/g06.ppt, marzo de 2005.

Dalal-Clayton, Barry y Barry Sadler (1999), "Strategic Environmental Assessment: A Rapidly Evolving Approach. Inter- 
national Institute for Environment and Development", Environmental Planning Issues, 18, http:/www.poptel.org. uk/iied/docs/spal/epi18.pdf, abril de 2005.

Department for Environment, Food and Rural Affairs (2005), Sustainable Development Indicators in your Pocket 2005, http://www.sustainable-development.gov.uk/performance/ documents/sdiyp2005_a6.pdf, agosto de 2005.

Esty, Daniel, Marc Levi, Tanja Srebotnjak y Alexander de Sherbinin (2005), 2005 Environmental Sustainability Index: Benchmarking National Environmental Stewardship, Yale Center for Environmental Law \& Policy, New Haven, http://www.yale.edu/esi/, febrero de 2005.

Environment Canada (2003), Environmental Signals: Canada's National Environmental Indicator Series 2003, http:// www.ec.gc.ca/soer-ree/English/Indicator_series/ esignals.pdf, agosto de 2005 .

Foladori, Guillermo y Humberto Tommasino (2005), "El enfoque técnico y social de la sustentabilidad", en Guillermo Foladori y Naína Pierri, ¿Sustentabilidad? Desacuerdos sobre el desarrollo sustentable, Miguel Ángel Porrúa-Universidad Autónoma de Zacatecas, México, pp. 197-206.

INEGI (Instituto Nacional de Estadística, Geografía e Informática) (1999), Sistema de Cuentas Económicas y Ecológicas de México: 1988-1996, INEGI, México.

(2000a), Sistema de Cuentas Económicas y Ecológicas de México: 1993-1999, Marco conceptual y metodológico, INEGI, México.

(2000b), Indicadores de Desarrollo Sustentable en México, http://www.inegi.gob.mx/prod_serv/contenidos/espanol/bvinegi/productos/integracion/especiales/indesmex/ 2000/ifdm2000F.pdf, pp. 1-203.

(2004), Sistema de Cuentas Económicas y Ecológicas de México 1997-2002, INEGI, México, pp. 1-172. 
(2005), Consulta electrónica, atención a usuarios, http:// www.inegi.gob.mx/lib/buzon.asp? s= prod_serv.enero de 2005 , enero de 2005.

Instituto Brasileño de Geografía y Estadística (2005), http:// www.ibge.gov.br, agosto de 2005.

Kessler, Jan Joost (2003), Strategic Environmental Analysis (Sean). -short version- AID Environment (Advice and Research for Development and Environment), http://www. aidenvironment.org, octubre de 2004.

La Jornada (2005), "Aumentaron 24\% en 2004 las remesas de mexicanos en el extranjero: Ídem", http://www.jornada. unam.mx/2005/feb05/050201/023n1eco.php, febrero de 2005.

Martínez, Anabel (2000), "La información del Sistema de Cuentas Económicas y Ecológicas en México: algunos usos y desafíos en la elaboración de estadísticas ambientales”, Papeles de Población, Instituto Nacional de Ecología-Centro de Investigación y Estudios de la población-Universidad Autónoma del Estado de México, 24: 95-112.

(2002), "Indicadores de sustentabilidad ambiental de la economía mexicana”, Comercio Exterior, 52 (3): 246-253.

Ministerio de la Salud y Ambiente de la Nación/Secretaría de Ambiente y Desarrollo Sustentable, Argentina (2004), http://www.medioambiente.gov.ar/documentos/ a g e n d a a m b i e n t a l/a c c i o n e s/ indicadores_desarrollo_sostenible/documento _proyecto.pdf, agosto de 2005 .

Ministerio de Medio Ambiente, Colombia (2005), Sistema de Indicadores de Sostenibilidad Ambiental, http:// www.minambiente.gov.co/sisa, agosto de 2005.

Ministerio de Medio Ambiente, España (2005), http:// w w w. m m a.es/info_a m b/indicadores/ bancoindicadores.htm, agosto de 2005 . 
Ministerio de Planificación Nacional y Política Económica, Costa Rica (2005), Sistema de Indicadores sobre Desarrollo Sostenible, http://www.mideplan.go.cr/sides/ index.html?63,58, agosto de 2005 .

Moreno, O. (2003), Facultad de Ciencias Económicas y Sociales, San Salvador, http://server2.southlink.com.ar/vap/ componentes.htm, enero de 2005.

Naciones Unidas (2002), Contabilidad ambiental y económica integrada. Manual de operaciones, Estudios de métodos. Manual de contabilidad nacional, Naciones Unidas, Nueva York, pp. 1-171.

Netherlands Ministry of Housing, Spatial Planning and the Environment (2005), http://international.vrom.nl/pagina. html?id=7358, agosto de 2005.

Nierynck, Eddy (s/f), Strategic Environmental Assessment. Project no. VNM/B7 - 6200/IB/96/05 European Commission DG1B "Environment in Developing Countries" programme, http://minf.vub.ac.be/ gronsse/Vietnam/EU/ EIAws1_12.html, octubre de 2004.

Nieto, Luz María (2002), ‘CCómo sabemos si tenemos avances hacia el desarrollo sostenible?', artículo de divulgación basado parcialmente en el reporte de investigación "La construcción regional del desarrollo sustentable y la educación superior", Pulso, diario de San Luis, http:// ambiental.uaslp.mx/docs/LMNC-AP000799.pdf, pp. 1-15, junio de 2004.

OECD (Organisation for Economic Co-operation and Development) (2005), http://www.oecd.org/document/58/0,2340, en_2649_201185_1889402_1_1_1_1,00.htm, enero de 2005 .

Official Government Reports, Suecia (1998 y 1999), Green Headline Indicators-Monitoring Progress towards Ecological Sustainability, http://www.sou.gov.se/mvb/english/pdf/ green_hdl_indictrs.pdf, agosto de 2005. 
Patterson, Murray (2002), Headline Indicators for Tracking Progress to Sustainability in New Zealand, http:// www.mfe.govt.nz/publications/ser/tech-report-71-sustainability-mar02.pdf, agosto de 2005.

Pearce, David y Giles Atkinson (1993), “Capital Theory and Measurement of Sustainable Development: An Indicator of 'Weak' Sustainability”, Ecological Economics, 8: 103108.

Quiroga, Rayén (2001), Indicadores de sostenibilidad ambiental $y$ de desarrollo sostenible: estado del arte y perspectivas, División de Medio Ambiente y Asentamientos Humanos, Naciones Unidas-Comisión Económica para América Latina y el Caribe, Serie Manuales, Santiago de Chile, pp. 101-116.

Sadler, Barry (1996), "SEA-Experience, Status and Directions for Improved Effectiveness", Environmental Assessment in a Changing World: Evaluating Practice to Improve Performance, Final Report of the International Study of the Effectiveness of Environmental Assessment, Ministry of Supply and Services Canada, Canadá, pp. 139-182.

Schedler, Andreas (2004), “¿Qué es la rendición de cuentas?”, Cuadernos de Transparencia, núm. 3, Instituto Federal de Acceso a la Información Pública (IFAI), México.

Seht, Hauke von (1999), "Requirements of a Comprehensive Strategic Environmental Assessment System”, Landscape and Urban Planning, septiembre, 45 (1): 1-14.

Ugalde, Luis Carlos (2002), Rendición de cuentas y democracia. El caso de México, Instituto Federal Electoral, México.

UNEP (United Nations Environment Programme) (s/f), Topic 14. Strategic Environmental Assessment, http://www.unep.ch/ etu/publications/EIA_2ed/EIA_E_top14_body.PDF, octubre de 2004.

U.s. Interagency Working Group on Sustainable Development Indicators Washington, D.c. (2001), Sustainable Develop- 
ment in the United States: An Experimental Set of Indicators, http://www.sdi.gov/lpBin22/lpext.dll/Folder1/Infoba se $7 / 1$ ? fn $=$ main-j.htm $\& \mathrm{f}=$ templates $\& 2.0$, agosto de 2005 .

Recibido: 29 de junio de 2005. Aceptado: 13 de agosto de 2005.

Patricia Rivera cursa en la actualidad el doctorado en estudios del desarrollo en la Universidad Autónoma de Zacatecas. Su línea de investigación se centra en el medio ambiente. Ha publicado, también con Guillermo Foladori, "Migración y sustentabilidad. Una mirada desde Zacatecas", en La Jornada Ecológica, México D.F., 4 de julio de 2005.

Guillermo Foladori es doctor en economía por la Universidad Nacional Autónoma de México. Fue profesor visitante en el Doctorado en Medio Ambiente y Desarrollo en la Universidad Federal de Paraná (Brasil) y en la Universidad de Columbia (Estados Unidos), y actualmente se desempeña como profesor en el Doctorado en Estudios del Desarrollo de la Universidad Autónoma de Zacatecas. Especialista en temas de ambiente y desarrollo, salud y desarrollo, y nanotecnología. Es autor de: Controversias sobre sustentabilidad. La coevolución sociedad-naturaleza, Miguel Ángel Porrúa editor y librero, México, 2001; con Naina Pierri, ¿̇Sustentabilidad? Desacuerdos sobre el desarrollo sustentable, Miguel Ángel Porrúa editor y librero, México, 2005; Por una sustentabilidad alternativa, Unión Internacional de los Trabajadores de la Alimentación y Afines, Montevideo, 2005; y con N. Invernizzi, "Nanotechnology and the Developing World. Will Nanotechnology Overcome Poverty or Widen Disparities?", $\mathrm{Na}$ notechnology Law \& Business Journal, 2 (3): 101-110, 2005, entre sus publicaciones más recientes. 